\title{
LIMONOIDES ISOLADOS DOS FRUTOS DE Carapa guianensis Aublet (Meliaceae)
}

\author{
Suniá Gomes Silva* e Rita de Cássia Saraiva Nunomura \\ Departamento de Química, Universidade Federal do Amazonas, Av. Gal. Rodrigo Octávio Jordão Ramos, 3000, Campus \\ Universitário, 69077-000 Manaus - AM, Brasil \\ Sergio Massayoshi Nunomura \\ Coordenação de Pesquisas em Tecnologia e Inovação, Instituto Nacional de Pesquisas da Amazônia, Av. André Araújo, 2936, \\ 69060-001 Manaus - AM, Brasil
}

Recebido em 16/1/12; aceito em 16/6/12; publicado na web em 31/8/12

\begin{abstract}
LIMONOIDS ISOLATED FROM FRUITS OF Carapa guianensis Aublet (Meliaceae). Six limonoids were isolated in hexane extract obtained from the seeds and pericarps of Carapa guianensis. The structures of the limonoids were determined based on the analysis of High Resolution Mass Spectroscopy and Nuclear Magnetic Resonance (uni-and bi-dimensional experiments) data. This is the first report of isolation of the limonoid $6 \alpha$-acetoxy-7-deacetilgedunin from the seeds of the C. guianensis species. The limonoid 6-hydroxy-methyl angolensate was also described for the first time in this species.
\end{abstract}

Keywords: Meliaceae; Carapa guianensis, limonoids.

\section{INTRODUÇÃO}

A família Meliaceae é caracterizada pela presença de substâncias conhecidas como limonoides, metabólitos que apresentam uma gama de atividades biológicas, principalmente inseticidas. ${ }^{1}$ Duas espécies dessa família que apresentam grande acúmulo de limonoides são a Carapa guianensis Aublet e a Carapa procera D. C. No Brasil, essas espécies ocorrem em várzeas e terra firme na Floresta Amazônica e são conhecidas popularmente como "andiroba". ${ }^{1-3}$

Das sementes de ambas as espécies, Carapa guianensis e C. procera, é extraído o conhecido óleo de andiroba, frequentemente sem se certificar de qual espécie de Carapa o óleo foi extraído. O óleo de andiroba é amplamente utilizado na medicina popular, principalmente como analgésico e anti-inflamatório. ${ }^{1,2}$ Em estudos científicos, o óleo de andiroba apresentou atividade inseticida frente ao Aedes aegypti, ${ }^{4}$ propriedades repelentes, ${ }^{5,6}$ baixo potencial teratogênico, ${ }^{7}$ atividade acaricida,${ }^{8}$ atividade antimalárica frente ao Plasmodium falciparum, ${ }^{9}$ atividade vermicida, ${ }^{10}$ efeitos antiedematogênicos, ${ }^{11}$ atividade antialérgica, analgésica e anti-inflamatória. ${ }^{12}$

Esse óleo pode ser obtido da maneira tradicional, cozinhando as sementes inteiras, separando as amêndoas das cascas e extraindo o óleo das amêndoas ou, através da prensagem mecânica das amêndoas e cascas trituradas juntas. ${ }^{3,13} \mathrm{O}$ óleo de andiroba é constituído principalmente de material saponificável, onde se destacam derivados dos ácidos graxos palmítico, oleico, esteárico e linoleico. Contudo, o óleo de andiroba contém normalmente cerca de $5 \%$ de material insaponificável, no qual se destacam os limonoides $17 \beta$-hidroxiazadiradiona, xiloccesina $\mathrm{k}$, gedunina, 6- $\alpha$-acetoxigedunina, 7-desacetoxi-7-oxogedunina, 1,2-di-hidro-3- $\beta$-hidroxi-7-desacetoxi-7-oxogedunina e angolensato de metila. ${ }^{1,11}$ Das sementes, dos galhos e do tronco da espécie C. guianensis foram isolados limonoides, flavonoides, flavanas, cumarinas, triterpenos, triacilglicerídeos, monoacilglicerídeos, metilbenzoatos e ácidos graxos saturados. ${ }^{11,14-16}$ Das sementes da C. procera também foram isolados alguns limonoides. ${ }^{17-21}$

Neste trabalho, o estudo químico de C. guianensis levou ao isolamento de limonoides presentes nas amêndoas e pericarpos da

*e-mail: sunisilva@ibest.com.br espécie, sendo que o estudo do pericarpo é inédito. Foram isolados e identificados os limonoides $6 \alpha$-acetoxigedunina (1), 7-desacetoxi-7-oxogedunina (2), 7-desacetilgedunina (5) e 6 $\alpha$-acetoxi-7desacetilgedunina (6) (ácido 16, 17-seco-24-nor-5 $\alpha, 13 \alpha, 14 \beta$, $17 \alpha$-chola-1, 20, 22-trien-16-oico, 14, 15 $\beta$ :21, 23-diepoxi-6 $\alpha, 7 \alpha$, 17-tri-hidroxi-4, 4, 8-trimetil-3-oxo-, 16, 17-lactona, 6-acetato) do óleo extraído das amêndoas e os limonoides angolensato de metila (3) e 6-hidroxi-angolensato de metila (4) isolados do extrato hexânico do pericarpo. O limonoide $\mathbf{6}$ está sendo descrito pela primeira vez nas amêndoas da espécie $C$. guianensis e o limonoide $\mathbf{4}$ foi isolado pela primeira vez nessa espécie.

\section{PARTE EXPERIMENTAL}

\section{Procedimentos experimentais gerais}

Os espectros de $\mathrm{RMN}{ }^{1} \mathrm{H}$ e ${ }^{13} \mathrm{C}$, uni e bidimensionais foram obtidos em um espectrômetro modelo Unity Inova da marca Varian Inc., operando na frequência de $500 \mathrm{MHz}$ para hidrogênio $\left({ }^{1} \mathrm{H}\right)$ e $125 \mathrm{MHz}$ para carbono-13 $\left({ }^{13} \mathrm{C}\right) . \mathrm{O} \mathrm{CDCl}_{3}$ (Cambridge Isotope Laboratories Inc.) foi utilizado como solvente em todas as aquisições de RMN. Os espectros de massas de alta resolução foram obtidos em espectrômetro da marca Bruker GmbH, modelo MicrOTOF II com fonte ESI e analisador de alta resolução TOF, no modo positivo. As análises em CLAE foram efetuadas em cromatógrafo líquido semipreparativo da marca Shimadzu, equipado com duas bombas LC-6AD, um degaseificador DGU-14A, um detector de UV-visível com dois canais SPD-10Avp, um controlador SCL-10Avp e um injetor manual Rheodyne, modelo 7725i. A aquisição dos dados foi feita utilizando o programa CLASS-VP versão 6.13 SP2. Uma coluna semipreparativa da Shimadzu Inc. SHIM-PACK PREP-ODS H (250 mm x 20 mm de $5 \mu \mathrm{m})$ foi utilizada. Para as separações cromatográficas empregando coluna flash utilizou-se sílica gel 60 (Merck, 230-400 mesh ASTM) e para cromatografia em coluna (CC) utilizou-se sílica gel 60 (Merck, 70-230 mesh ASTM). Nas análises por cromatografia em camada delgada (CCD) foram utilizadas placas de sílica gel $60 \mathrm{PF}_{254}$. As placas de CCD foram observadas sob luz UV 254 e $366 \mathrm{~nm}$ e reveladas com vapores de iodo ressublimado e solução de anisaldeído, seguida de aquecimento. As placas preparativas (CCDP) foram preparadas 
usando sílica gel $60 \mathrm{PF}_{254}$ em placas de vidro de 20 x $20 \mathrm{~cm}$ e com $1 \mathrm{~mm}$ de espessura de sílica. As placas foram secas à temperatura ambiente e ativadas em uma estufa à $100^{\circ} \mathrm{C}$ por $3 \mathrm{~h}$.

\section{Material botânico}

Os frutos de C. guianensis Aublet. foram coletados em março de 2008, na Reserva Florestal Adolpho Ducke, que pertence ao Instituto Nacional de Pesquisas da Amazônia (INPA), situada no km 26 da rodovia AM-010, que liga Manaus a Itacoatiara, Amazonas. As exsicatas dos indivíduos coletados encontram-se depositadas no Herbário do INPA (Manaus, AM), sob catálogo números 178.658 e 192.616.

\section{Extração e isolamento}

As amêndoas descascadas (505 g) e os pericarpos (114 g) retirados e separados cuidadosamente dos frutos foram secos em estufa a $60{ }^{\circ} \mathrm{C}$ e posteriormente triturados. Em seguida, os materiais foram submetidos separadamente para a extração em aparelho de Soxhlet (3 vezes por $8 \mathrm{~h}$ ), sucessivamente, com hexano, $\mathrm{CHCl}_{3}, \mathrm{AcOEt}$ e $\mathrm{MeOH}$. Após as extrações com hexano, as soluções hexânicas das amêndoas e do pericarpo, à temperatura ambiente, apresentaram precipitados (sólidos amorfos brancos). Esses precipitados foram submetidos separadamente à filtração e, posteriormente, recristalizados em $\mathrm{MeOH}$ a frio. Os cristais formados da solução metanólica dos precipitados da extração hexânica das amêndoas e os cristais formados da solução metanólica dos precipitados da extração hexânica do pericarpo foram separados por filtração e solubilizados em $\mathrm{CHCl}_{3}$. Após a evaporação dos solventes sob pressão reduzida, obtiveram-se $1,9 \mathrm{~g}$ de precipitado (P1), 223 mg de cristais (C1) (extração hexânica das amêndoas) e $1,0 \mathrm{~g}$ de precipitado (P2), 73 mg de cristais (C2) (extração hexânica do pericarpo).

Os cristais $\mathrm{C} 1$ (extrato hexânico das amêndoas) foram fracionados em $\mathrm{CC}$ de sílica gel 60 empregando misturas de $\mathrm{CHCl}_{3} /$ AcOEt (97:3; 95:5; 90:10 e 85:15), $\mathrm{CHCl}_{3} / \mathrm{i}-\mathrm{PrOH}$ (90:10) e com $\mathrm{MeOH}$ puro, gerando 65 frações, que após analisadas por CCD foram reunidas em 7 frações $(\mathrm{C} 1-\mathrm{A}$ a $\mathrm{C} 1-\mathrm{G})$. Da reunião $\mathrm{C} 1-\mathrm{D}$ foi isolada uma mistura das substâncias 1 e 2 (127 mg), após purificação por CCDP com o eluente $\mathrm{CHCl}_{3} / \mathrm{AcOEt}(85: 15)$. Os cristais C2 (extrato hexânico do pericarpo) foram purificados através de CCDP com o eluente $\mathrm{CHCl}_{3} / \mathrm{AcOEt}$ (80:20) fornecendo as substâncias $3(16 \mathrm{mg})$ e $4(17 \mathrm{mg})$. Fracionou-se 1,5 g do precipitado P1 (oriundo do extrato hexânico das amêndoas) em CC de sílica gel 60 empregando as misturas $\mathrm{CHCl}_{3} / \mathrm{Me}_{2} \mathrm{CO}$ (95:5; 90:10 e 85:15), $\mathrm{CHCl}_{3} / \mathrm{MeOH}$ (95:5) e com MeOH puro, gerando 26 frações, que após analisadas por CCD foram reunidas em 8 frações (P1-A a P1$\mathrm{H})$. A reunião $\mathrm{P} 1-\mathrm{D}$ foi submetida a um fracionamento em $\mathrm{CC}$ de sílica gel 60 empregando o eluente DCM/Me ${ }_{2} \mathrm{CO} / \mathrm{MeOH}$ (90:10:6 gotas) e com $\mathrm{MeOH}$ puro, gerando 51 frações, que foram reunidas em 8 frações (P1-D1 a P1-D8) após serem analisadas em CCD. A reunião $\mathrm{P} 1-\mathrm{D} 2$ foi submetida a um fracionamento por cromatografia em coluna flash de sílica gel 60 empregando misturas de Hex/ $\mathrm{CHCl}_{3}(80: 20 ; 70: 30 ; 60: 40$ e 50:50) e finalizando com $\mathrm{MeOH}$ puro, gerando 85 frações, que após analisadas em CCD foram reunidas em 10 frações (P1-D2A a P1-D2J). A reunião P1-D2E foi fracionada através de CCDP com o eluente $\mathrm{CHCl}_{3} / \mathrm{Me}_{2} \mathrm{CO}$ (95:5) fornecendo a fração P1-D2E1, contendo a mistura das substâncias 5 e 6 (10 mg). Posteriormente, a fração P1-D2E1 foi purificada em CLAE semipreparativo, utilizando como fase móvel a mistura dos solventes $\mathrm{MeOH} / \mathrm{H}_{2} \mathrm{O}$ (68:32), em condição isocrática, com fluxo de $15 \mathrm{~mL} / \mathrm{min}$. Para a detecção dos picos de interesse foi utilizado o comprimento de onda de $210 \mathrm{~nm}$ para as substâncias $\mathbf{5}$ ( $\mathrm{tr}=19,6$ $\mathrm{min} ; 1,3 \mathrm{mg})$ e 6 ( $t r=26,8 \mathrm{~min} ; 1,0 \mathrm{mg})$.
Mistura das substâncias 6م-acetoxigedunina (1) e 7-desacetoxi-7oxogedunina (2)

Cristais incolores. HR-ESI-MS $\mathrm{m} / \mathrm{z}$ 563,22535 [valor calculado para $\mathrm{C}_{30} \mathrm{H}_{36} \mathrm{O}_{9} \mathrm{Na}[\mathrm{M}+\mathrm{Na}]^{+}$foi de 563,22515 para a $6 \alpha$-acetoxigedunina (1)]. HR-ESI-MS m/z, 461,19347 [valor calculado para $\mathrm{C}_{26} \mathrm{H}_{30} \mathrm{O}_{6} \mathrm{Na}$ $[\mathrm{M}+\mathrm{Na}]^{+}$foi de 461,19345 para a 7-desacetoxi-7-oxogedunina (2)]. Os dados de $\mathrm{RMN}{ }^{13} \mathrm{C}$ e ${ }^{1} \mathrm{H}\left(\mathrm{CDCl}_{3}\right)$ foram comparados e estão de acordo com os da literatura. ${ }^{22}$

Angolensato de metila (3)

Sólido amorfo amarelo. HR-ESI-MS $\mathrm{m} / \mathrm{z}, 493,21973$ (o valor calculado para $\mathrm{C}_{27} \mathrm{H}_{34} \mathrm{O}_{7} \mathrm{Na}[\mathrm{M}+\mathrm{Na}]^{+}$foi de 493,21967). Os dados de $\mathrm{RMN}{ }^{13} \mathrm{C}$ e ${ }^{1} \mathrm{H}\left(\mathrm{CDCl}_{3}\right)$ foram comparados e estão de acordo com os da literatura. ${ }^{22}$

\section{6-hidroxi-angolensato de metila (4)}

Cristais incolores. HR-ESI-MS m/z 509, 21502 (o valor calculado para $\mathrm{C}_{27} \mathrm{H}_{34} \mathrm{O}_{8} \mathrm{Na}[\mathrm{M}+\mathrm{Na}]^{+}$foi de 509,21458$)$. Os dados de $\mathrm{RMN}{ }^{13} \mathrm{C}$ e ${ }^{1} \mathrm{H}\left(\mathrm{CDCl}_{3}\right)$ são apresentados nas Tabelas 1 e 2, foram comparados e estão de acordo com os da literatura. ${ }^{23}$

Tabela 1. Deslocamentos químicos de $\mathrm{RMN}{ }^{13} \mathrm{C}(\mathrm{CDCl} 3)$ dos limonoides 4-6

\begin{tabular}{|c|c|c|c|}
\hline $\mathrm{C}$ & 4 & 5 & 6 \\
\hline 1 & 78,5 & 158,1 & 157,0 \\
\hline 2 & 39,4 & 126,1 & 126,8 \\
\hline 3 & 212,3 & 204,0 & 204,2 \\
\hline 4 & 48,9 & 44,1 & 45,2 \\
\hline 5 & 47,8 & 45,0 & 46,9 \\
\hline 6 & 72,6 & 27,6 & 72,4 \\
\hline 7 & 176,8 & 70,0 & 72,2 \\
\hline 8 & 146,2 & 44,0 & 43,8 \\
\hline 9 & 51,1 & 38,3 & 37,1 \\
\hline 10 & 44,9 & 40,5 & 41,0 \\
\hline 11 & 24,3 & 15,3 & 15,6 \\
\hline 12 & 28,8 & 26,7 & 27,0 \\
\hline 13 & 41,6 & 38,6 & 39,0 \\
\hline 14 & 80,6 & 70,2 & 69,2 \\
\hline 15 & 33,9 & 58,1 & 59,3 \\
\hline 16 & 170,2 & 168,7 & 168,5 \\
\hline 17 & 79,6 & 78,8 & 78,9 \\
\hline 18 & 14,0 & 18,1 & 17,9 \\
\hline 19 & 23,6 & 20,1 & 21,8 \\
\hline 20 & 121,0 & 119,0 & 121,0 \\
\hline 21 & 141,0 & 141,1 & 141,5 \\
\hline 22 & 110,6 & 110,1 & 110,3 \\
\hline 23 & 142,9 & 143,0 & 143,5 \\
\hline 28 & 24,9 & 21,8 & 31,5 \\
\hline 29 & 23,9 & 27,5 & 21,0 \\
\hline 30 & 111,8 & 18,9 & 17,9 \\
\hline $6-\mathrm{OCOCH}_{3}$ & - & - & 22,0 \\
\hline $6-\mathrm{OCOCH}_{3}$ & - & - & 170,1 \\
\hline $\mathrm{OCH}_{3}$ & 53,7 & - & - \\
\hline
\end{tabular}

\section{7-desacetilgedunina $\mathbf{( 5 )}$}

Sólido amorfo branco. HR-ESI-MS $\mathrm{m} / \mathrm{z}, 463,20765$ (o valor calculado para $\mathrm{C}_{26} \mathrm{H}_{32} \mathrm{O}_{6} \mathrm{Na}[\mathrm{M}+\mathrm{Na}]^{+}$foi de 463,20910 . Os dados de $\mathrm{RMN}{ }^{13} \mathrm{C}$ e ${ }^{1} \mathrm{H}\left(\mathrm{CDCl}_{3}\right)$ foram comparados e estão de acordo com os da literatura. ${ }^{1}$ 
Tabela 2. Deslocamentos químicos de $\mathrm{RMN}^{1} \mathrm{H}(\mathrm{CDCl} 3)$ dos limonoides 4 - 6

\begin{tabular}{|c|c|c|c|}
\hline No. & 4 & 5 & 6 \\
\hline 1 & $3,56(\mathrm{dd}, 5,5 ; 2,0)$ & $7,11(\mathrm{~d}, 10,5)$ & $7,06(d, 10,0)$ \\
\hline 2 & $\begin{array}{l}\alpha 2,34(\mathrm{dd}, 14,0 ; 2,0) \\
\beta 3,11(\mathrm{dd}, 14,0 ; 5,5)\end{array}$ & $5,85(\mathrm{~d}, 10,5)$ & $5,92(\mathrm{~d}, 10,0)$ \\
\hline 5 & 2,73(sl) & $2,48(\mathrm{dd}, 13,0 ; 2,0)$ & $2,73(\mathrm{~d}, 12,0)$ \\
\hline 6 & $4,41(\mathrm{sl})$ & $\begin{array}{l}\alpha 1,88(\mathrm{~m}) \\
\beta 1,84(\mathrm{~m})\end{array}$ & $5,31(\mathrm{dd}, 12,0 ; 2,0)$ \\
\hline 7 & - & $3,58(\mathrm{sl})$ & $3,46(\mathrm{sl})$ \\
\hline 9 & $2,31(\mathrm{dd}, 5,0 ; 2,0)$ & $2,52(\mathrm{dd}, 12,5 ; 6,0)$ & $2,59(\mathrm{dd}, 12,5 ; 6,0)$ \\
\hline 11 & $\begin{array}{c}1,56(\mathrm{ddd}, 14,0 ; 9,0 ; 5,0) \\
2,12(\mathrm{~m})\end{array}$ & $\begin{array}{l}1,96(\mathrm{~m}) \\
1,74(\mathrm{~m})\end{array}$ & $\begin{array}{l}1,95(\mathrm{~m}) \\
1,90(\mathrm{~m})\end{array}$ \\
\hline 12 & $\begin{array}{c}1,01(\mathrm{dd}, 5,0 ; 1,5) \\
1,72(\mathrm{ddd}, 14,0 ; 14,0 \\
5,0)\end{array}$ & $\begin{array}{l}1,64(\mathrm{~m}) \\
1,88(\mathrm{~m})\end{array}$ & $\begin{array}{l}1,53(\mathrm{~m}) \\
1,72(\mathrm{~m})\end{array}$ \\
\hline 15 & $\begin{array}{l}2,58(\mathrm{~d}, 18,0) \\
2,90(\mathrm{~d}, 18,0)\end{array}$ & $3,92(\mathrm{~s})$ & $3,87(\mathrm{~s})$ \\
\hline 17 & $5,62(\mathrm{~s})$ & $5,61(\mathrm{~s})$ & $5,61(\mathrm{~s})$ \\
\hline 18 & $0,87(\mathrm{~s})$ & $1,24(\mathrm{~s})$ & $1,26(\mathrm{~s})$ \\
\hline 19 & $1,39(\mathrm{~s})$ & $1,20(\mathrm{~s})$ & $1,18(\mathrm{~s})$ \\
\hline 21 & $7,46(\mathrm{dl}, 0,5)$ & $7,41(\mathrm{~m})$ & $7,41(\mathrm{~m})$ \\
\hline 22 & $6,36(\mathrm{dl}, 1,5)$ & $6,36(\mathrm{~m})$ & $6,35(\mathrm{~m})$ \\
\hline 23 & $7,37(\mathrm{t}, 1,5)$ & $7,41(\mathrm{~m})$ & $7,41(\mathrm{~m})$ \\
\hline 28 & $1,05(\mathrm{~s})$ & $1,10(\mathrm{~s})$ & $1,27(\mathrm{~s})$ \\
\hline 29 & $1,45(\mathrm{~s})$ & $1,15(\mathrm{~s})$ & $1,17(\mathrm{~s})$ \\
\hline 30 & $4,91(\mathrm{~s}) ; 5,19(\mathrm{~s})$ & $1,09(\mathrm{~s})$ & $1,19(\mathrm{~s})$ \\
\hline $6-\mathrm{OCOC} \underline{\mathrm{H}}_{3}$ & - & - & $2,17(\mathrm{~s})$ \\
\hline $\mathrm{OC}_{3}$ & $3,83(\mathrm{~s})$ & - & - \\
\hline
\end{tabular}

6 $\alpha$-acetoxi-7-desacetilgedunina (6) (ácido 16, 17-seco-24-nor$5 \alpha, 13 \alpha, 14 \beta, 17 \alpha$-chola-1, 20, 22-trien-16-oico, 14, 15 $\beta: 21$, 23-diepoxi-6 $\alpha, 7 \alpha$, 17-trihidroxi-4, 4, 8-trimetil-3-oxo-, 16,

\section{7-lactona, 6-acetato)}

Sólido amorfo branco. HR-ESI-MS $\mathrm{m} / \mathrm{z}, 521,21471$ (o valor calculado para $\mathrm{C}_{28} \mathrm{H}_{34} \mathrm{O}_{8} \mathrm{Na}[\mathrm{M}+\mathrm{Na}]^{+}$foi de 521,21458$)$. Os dados de $\mathrm{RMN}{ }^{13} \mathrm{C}$ e ${ }^{1} \mathrm{H}\left(\mathrm{CDCl}_{3}\right)$ estão descritos nas Tabelas 1 e 2, foram comparados e estão de acordo com os da literatura. ${ }^{24,25}$

\section{RESULTADOS E DISCUSSÃO}

O estudo químico das amêndoas (descascadas) dos frutos de Carapa guianensis permitiu o isolamento de uma mistura dos limonoides $6 \alpha$-acetoxigedunina (1) e 7-desacetoxi-7-oxogedunina (2) e dos limonoides 7-desacetilgedunina (5) e 6 6 -acetoxi-7desacetilgedunina (6). A investigação fitoquímica inédita do pericarpo dos frutos conduziu ao isolamento dos limonoides angolensato de metila (3) e 6-hidroxi-angolensato de metila (4) (Figura 1).

O limonoide 6 é descrito pela primeira vez nas amêndoas da espécie $C$. guianensis e o limonoide 6-hidroxi-angolensato de metila (4) é descrito pela primeira vez nessa espécie. As estruturas de $\mathbf{1}$ a 6 foram determinadas por $\mathrm{RMN}{ }^{1} \mathrm{H}$ e ${ }^{13} \mathrm{C}$, incluindo experimentos bidimensionais (COSY, HSQC e HMBC). Os experimentos realizados com espectros de massas de alta resolução (HR-ESI-MS) permitiram confirmar as fórmulas moleculares propostas por RMN para todas as substâncias.

Os limonoides 1, 2 e $\mathbf{3}$ foram identificados com base na comparação dos dados espectrais de RMN obtidos com os dados descritos na literatura. ${ }^{22}$

As fórmulas moleculares $\mathrm{C}_{26} \mathrm{H}_{32} \mathrm{O}_{6}$ e $\mathrm{C}_{28} \mathrm{H}_{34} \mathrm{O}_{8}$ da mistura dos limonoides 5 e 6, respectivamente, foram determinadas com base na análise do HR-ESI-MS [M+Na] ${ }^{+} \mathrm{m} / \mathrm{z}$ 463,20765, calculado $\mathrm{m} / \mathrm{z}$.
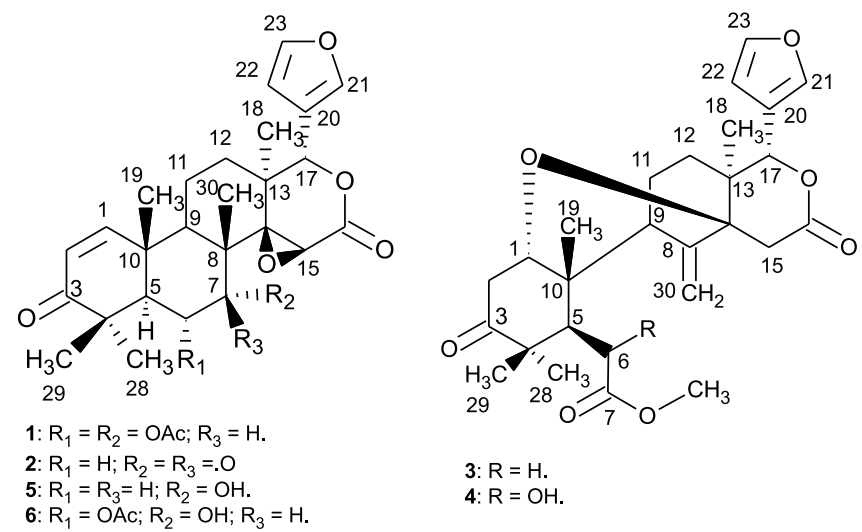

Figura 1. Estruturas dos limonoides isolados de C. guianensis

463,20910 para 5 e $\mathrm{m} / \mathrm{z}$ 521,21471, calculado $\mathrm{m} / \mathrm{z}$ 521,21458 para 6. O espectro de RMN ${ }^{1} \mathrm{H}$ da mistura de 5 e $\mathbf{6}$ mostrou sinais característicos de ligação dupla de anéis cicloexenonas do tipo $\alpha, \beta$-insaturada $[\delta 7,11$ (d), 7,06 (d), 5,92 (d) e 5,85 (d)], sinais de hidrogênios típicos de sistemas D-lactônicos [ $\delta 3,92$ (s) e 3,87 (s)], sinais de grupos metilas ligados a carbonos $\mathrm{sp}^{3}[\delta 1,27(\mathrm{~s}), 1,26(\mathrm{~s}), 1,24(\mathrm{~s}), 1,20(\mathrm{~s}), 1,19(\mathrm{~s})$, $1,18(\mathrm{~s}), 1,17$ (s), 1,15 (s), 1,10 (s) e 1,09 (s)], um sinal equivalente a hidrogênios de metila característicos de grupo acetoxi $[\delta 2,17(\mathrm{~s})]$, além de sinais típicos de hidrogênios carbinólicos $[\delta$ 5,31 (dd), 3,58 (dd) e 3,46 (dl)]. Em adição, verifica-se no espectro de $\mathrm{RMN}{ }^{13} \mathrm{C}$ a presença de sinais característicos de carbonos de carbonílas cetônicas e lactônicas [ $\delta 204,2,204,0,168,7$ e 168,5, respectivamente], de sinais de carbonos característicos de dois grupos epóxidos $[\delta 70,2,69,2$, 59,3 e 58,1], de sinais de carbonos carbinólicos [ $\delta 72,4,72,2$ e 70,0] e de um sinal de carbono típico de carboníla de éster [ $\delta 170,1]$. No espectro de HSQC foi atribuída a correlação do sinal do hidrogênio carbinólico em $\delta 5,31$ com o carbono C-6 $(\delta 72,4)$ e do sinal do hidrogênio carbinólico em $\delta 3,46$ com o carbono C-7 ( $\delta 72,2)$ para o limonoide $\mathbf{6}$, assim como a correlação do sinal do hidrogênio carbinólico em $\delta 3,58$ com o carbono C-7 $(\delta 70,0)$ para o limonoide $\mathbf{5}$.

Após a separação da mistura dos limonoides 5 e $\mathbf{6}$ em CLAE semipreparativo, a estrutura de $\mathbf{5}$ foi identificada pela análise dos espectros de RMN uni- e bidimensionais e a comparação com os dados da literatura. ${ }^{1} \mathrm{Na}$ análise do espectro de HSQC de $\mathbf{6}$ foi confirmada a correlação do sinal do hidrogênio carbinólico em $\delta$ 5,31 com o carbono C-6 $(\delta 72,4)$ e do sinal do hidrogênio carbinólico em $\delta 3,46$ com o carbono C-7 $(\delta 72,2)$. As correlações observadas no espectro de HMBC entre o sinal em $\delta 2,73$ (H-5) e o sinal em $\delta 72,4$ (C-6), entre o sinal em $\delta 1,19(\mathrm{H}-30)$ e o sinal em $\delta 72,2(\mathrm{C}-7)$ e entre o sinal em $\delta 2,16$ (hidrogênios da metila do grupo acetoxi) e o sinal em $\delta$ 170,1 (carbono carbonílico do grupo acetoxi) permitiram definir suas posições no limonoide 6. Em adição, o sinal em $\delta$ 5,31 (H-6) acopla com os sinais em $\delta 3,46(\mathrm{H}-7)$ e em $\delta 2,73$ (H-5) no espectro de COSY, reforçando as atribuições das posições desses hidrogênios e carbonos nesse limonoide. As constantes de acoplamento calculadas para os sinais dos hidrogênios H-5 (d, 12,0 Hz) e H-6 (dd, 12,0 e 2,0 $\mathrm{Hz}$ ) e o sinal observado para o hidrogênio H-7 (sl), observados na Tabela 2, estão de acordo com os valores de constantes de acoplamento apresentados na literatura para os acoplamentos axial-axial $(J 12 \mathrm{e}$ $13 \mathrm{~Hz}$ ), axial-equatorial e equatorial-equatorial $(J 1,5$ a $3,5 \mathrm{~Hz}) .^{24,25}$ Assim, esses dados permitem apresentar a estrutura mostrando a estereoquímica dos centros quirais C-5, C-6 e C-7 em como descrito em 6. Desse modo, o grupo hidroxila ligado em C-7 seria $\alpha$ (axial), o grupo acetoxi ligado em C-6 seria $\alpha$ (equatorial) e o hidrogênio H-5 seria $\alpha$ (axial, como esperado para uma junção dos anéis $\mathrm{A} / \mathrm{B}$ trans). A análise dos demais dados de $\mathrm{RMN}{ }^{1} \mathrm{H} \mathrm{e}{ }^{13} \mathrm{C}$ (Tabelas 1 e 2), bidimensionais, resultados obtidos em HR-ESI-MS e a comparação 
com os dados da literatura permitiram a identificação do limonoide 6 como $6 \alpha$-acetoxi-7-desacetilgedunina. ${ }^{25}$ Este é o primeiro relato do isolamento de $\mathbf{6}$ nas amêndoas da espécie $C$. guianensis.

A análise dos espectros de RMN ${ }^{1} \mathrm{H}$ e de ${ }^{13} \mathrm{C}$ do limonoide 4 mostrou grande similaridade estrutural com o limonoide 3 . A principal diferença está na presença de um sinal em $\delta 4,41$ no espectro de $\mathrm{RMN}{ }^{1} \mathrm{H}$ de 4 , atribuído a um hidrogênio carbinólico, claramente correlacionado com o carbono em $\delta 72,6$ no espectro de HSQC. No experimento de HMBC, a correlação observada entre o sinal em $\delta 2,73$ (H-5) e o sinal em $\delta 72,6$ (carbono sp $^{3}$ oxigenado C-6) permitiu correlacionar este sinal ao carbono $\mathrm{C}-6$ contendo um grupo hidroxila. Em adição, o sinal em $\delta 2,73$ (H-5) acopla com o sinal em $\delta 4,41$ no espectro de COSY, permitindo correlacionar este último ao hidrogênio H-6. Outras correlações foram observadas, com destaque para aquelas entre os sinais em $\delta 51,1(\mathrm{C}-9)$ e o sinal de hidrogênio em $\delta 2,31(\mathrm{H}-9)$ no espectro de HSQC e entre os sinais em $\delta 51,1(\mathrm{C}-9)$ e em $\delta 5,19$ e $\delta 4,91$ (dois hidrogênios metilênicos $\mathrm{sp}^{2}$ na posição 30 ) no espectro de HMBC. Essas observações feitas nos experimentos de HMBC e COSY indicam a posição do carbono carbinólico na posição 6 (Figura 1). A análise dos dados de $\mathrm{RMN}{ }^{1} \mathrm{H}$ e ${ }^{13} \mathrm{C}$ (Tabelas 1 e 2), bidimensionais, os resultados obtidos em HR-ESI-MS e a comparação com a literatura permitiram a identificação do limonoide 4 como 6-hidroxi-angolensato de metila. ${ }^{23}$ Este é o primeiro relato da ocorrência dessa substância nos frutos de andiroba.

\section{CONCLUSÕES}

O óleo de andiroba é um dos principais produtos extrativistas da biodiversidade amazônica. $\mathrm{O}$ seu interesse deve-se em grande parte ao acúmulo de limonoides nos frutos, de onde se extrai o óleo. A descrição de dois limonoides isolados pela primeira vez dos frutos da espécie Carapa guianensis (6-hidroxi-angolensato de metila e 6 -acetoxi-7-desacetilgedunina) é um importante acréscimo ao conhecimento da fitoquímica da espécie.

\section{MATERIAL SUPLEMENTAR}

As Tabelas com os dados de $\mathrm{RMN}{ }^{1} \mathrm{H}$ e ${ }^{13} \mathrm{C}$ para os limonoides $\mathbf{1}$ - 3, os espectros uni e bidimensionais das substâncias isoladas, a foto dos frutos da espécie $C$. guianensis e o cromatograma para o isolamento dos limonoides 5 e $\mathbf{6}$ encontram-se disponíveis em http:// quimicanova.sbq.org.br, na forma de arquivo PDF, com acesso livre.

\section{AGRADECIMENTOS}

Ao CT-Amazônia/CNPq pelo auxílio financeiro, à FAPEAM pela bolsa concedida e ao Prof. N. P. Lopes (FCF/USP-RP) pela aquisição dos espectros de massas de alta resolução.

\section{REFERÊNCIAS}

1. Ambrozin, A. R. P.; Leite, A. C.; Bueno, F. C.; Vieira, P. C.; Fernandes, J. B.; Bueno, O. C.; Silva, M. F. G. F.; Pagnocca, F. C.; Hebling, M. J. A.; Bacci Jr., M.; J. Braz. Chem. Soc. 2006, 17, 542.
2. Tappin, M. R. R.; Nakamura, M. J.; Siani, A. C.; Lucchetti, L.; J. Pharm. Biomed. Anal. 2008, 48, 1090.

3. Ferraz, I. D. K.; Camargo, J. L. C.; Sampaio, P. T. B. S.; Acta Amazonica 2002, 32, 647

4. Mendonça, F. A. C.; Silva, K. F. S.; Santos, K. K.; Ribeiro Júnior, K. A. L.; Sant'Ana, A. E. G.; Fitoterapia 2005, 76, 629.

5. Miot, H. A.; Batistella, R. F.; Batista, K. A.; Volparto, D. E. C.; Augusto, L. S. T.; Madeira, N. G.; Haddad Jr., V.; Miot, L. D. B.; Rev. Inst. Med. Trop. S. Paulo 2004, 46, 253.

6. Freire, D. da C. B.; Brito-Filha, C. R. da C.; Carvalho-Zilse, G. S.; Acta Amazonica 2006, 36, 365 .

7. Costa-Silva, J. H.; Lyra, M. M. A.; Lima, C. R.; Arruda, V. M.; Araújo, A. V.; Ribeiro e Ribeiro, A.; Arruda, A. C.; Fraga, M. C. C. A.; Lafayette, S. S. L.; Wanderley, A. G.; J. Ethnopharmacol. 2007, 112, 122.

8. Farias, M. P. O.; Sousa, D. P.; Arruda, A. C.; Wanderley, A. G.; Texeira, W. C.; Alves, L. C; Faustino, M. A. G.; Arq. Bras. Med. Vet. Zootec. 2009, 61, 877 .

9. Miranda Júnior, R. N. C.; Dissertação de Mestrado, Universidade Federal do Pará, Brasil, 2010.

10. Farias, M. P. O.; Wanderley, A. G.; Texeira, W. C.; Alves, L. C.; Faustino, M. A. G.; Rev. Bras. Pl. Med., Botucatu 2010, 12, 220.

11. Penido, C.; Costa, K. A.; Pennaforte, R. J.; Costa, M. F. S.; Pereira, J. F. G.; Siani, A. C.; Henriques, M. G. M. O.; Inflammation Res. 2005, 54, 295.

12. Henriques, M. G. M. O.; Monteiro, C. P.; Siani, A. C.; Guilhermino, J. F.; Ramos, M. F. S.; Sampaio, A. L. F.; Rosas, E. C.; De Lima, L. A.; Pennaforte, R. J.; PCT Int. Appl. WO 2006007680 A1 2006026, 2006.

13. da Silva, C. L. M.; Dissertação de Mestrado, Universidade Estadual de Campinas, Brasil, 2005.

14. Qi, S.; Wu, D.; Zhang, S.; Luo, X.; Pharmazie 2004, 59, 488.

15. Qi, S. H.; Wu, D. G.; Ma, Y. B.; Luo, X. D.; Acta Bot. Sin. 2003, 45, 1129.

16. Connolly, J. D.; McCrindle, R.; Overton, K. H.; Feeney, J.; Tetrahedron 1966, 22, 891

17. Mikolajczak, K. L.; Weisleder, D.; J. Nat. Prod. 1988, 51, 606.

18. Sondengam, B. L.; Kamba, C. S.; Kimbu, S. F.; Connolly, J. D.; Phytochemistry 1981, 20, 173.

19. Sondengam, B. L.; Kamba, C. S.; Connolly, J. D.; Phytochemistry 1980, $19,2488$.

20. Sondengam, B. L.; Kamba, C. S.; Connolly, J. D.; Tetrahedron Lett. 1979, 15, 1357.

21. Kimbu, S. F.; Ayalor, J. F.; Sondengam, B. L.; Connolly, J. D.; Rycroft, D. S. C.; Tetrahedron Lett. 1984, 25, 1613.

22. Kadota, S.; Marpaung, L.; Kikuchi, T.; Ekimoto, H.; Chem. Pharm. Bull. 1990, 38, 639 .

23. Abdelgaleil, S. A. M.; Okamura, H.; Iwagawa, T.; Sato, A.; Miyahara, I.; Doe, M.; Nakatani, M.; Tetrahedron 2001, 57, 119.

24. Ohochuku, N. S.; Taylor, D. A. H.; J. Chem. Soc. (C) 1970, 3, 421.

25. Tanaka, Y.; Sakamoto, A.; Inoue, T.; Yamada, T.; Kikuchi. T.; Kajimoto, T.; Muraoka, O.; Sato, A.; Wataya, Y.; Kim, H-S.; Tanaka, R.; Tetrahedron 2012, 68, 3669. 
Suniá Gomes Silva* e Rita de Cássia Saraiva Nunomura

Departamento de Química, Universidade Federal do Amazonas, Av. Gal. Rodrigo Octávio Jordão Ramos, 3000, Campus Universitário, 69077-000 Manaus - AM, Brasil

\section{Sergio Massayoshi Nunomura}

Coordenação de Pesquisas em Tecnologia e Inovação, Instituto Nacional de Pesquisas da Amazônia, Av. André Araújo, 2936, 69060-001 Manaus - AM, Brasil

Tabela 1S. Deslocamentos químicos de $\mathrm{RMN}{ }^{13} \mathrm{C}(\mathrm{CDCl} 3)$ dos limonoides $1-3$

\begin{tabular}{|c|c|c|c|}
\hline $\mathrm{C}$ & 1 & 2 & 3 \\
\hline 1 & 156,0 & 156,3 & 77,0 \\
\hline 2 & 126,7 & 126,8 & 39,6 \\
\hline 3 & 204,2 & 203,4 & 213,0 \\
\hline 4 & 45,2 & 45,4 & 48,3 \\
\hline 5 & 38,6 & 54,8 & 43,1 \\
\hline 6 & 69,8 & 36,9 & 32,9 \\
\hline 7 & 72,8 & 208,3 & 174,1 \\
\hline 8 & 43,8 & 53,6 & 146,0 \\
\hline 9 & 47,9 & 47,8 & 50,1 \\
\hline 10 & 40,8 & 39,8 & 44,2 \\
\hline 11 & 15,2 & 17,6 & 24,0 \\
\hline 12 & 26,1 & 32,4 & 29,5 \\
\hline 13 & 38,9 & 37,9 & 41,7 \\
\hline 14 & 48,0 & 65,8 & 80,4 \\
\hline 15 & 56,4 & 53,8 & 34,0 \\
\hline 16 & 167,3 & 167,0 & 170,2 \\
\hline 17 & 78,3 & 78,2 & 79,8 \\
\hline 18 & 18,1 & 20,8 & 14,0 \\
\hline 19 & 21,6 & 20,0 & 21,8 \\
\hline 20 & 120,4 & 120,5 & 121,0 \\
\hline 21 & 141,2 & 141,0 & 141,0 \\
\hline 22 & 110,0 & 109,9 & 110,1 \\
\hline 23 & 143,3 & 143,3 & 143,0 \\
\hline 28 & 31,6 & 27,2 & 26,1 \\
\hline 29 & 20,5 & 21,2 & 21,7 \\
\hline 30 & 18,3 & 17,4 & 111,7 \\
\hline $6-\mathrm{OCOCH}{ }_{3}$ & 21,4 & - & - \\
\hline 7- $\mathrm{OCOCH}_{3}$ & 21,1 & - & - \\
\hline 6- $\mathrm{OCOCH}_{3}$ & 170,3 & - & - \\
\hline 7- $\mathrm{OCOCH}_{3}$ & 170,2 & - & - \\
\hline $\mathrm{OCH}_{3}$ & - & - & 52,3 \\
\hline
\end{tabular}

Tabela 2S. Deslocamentos químicos de $\mathrm{RMN}{ }^{1} \mathrm{H}(\mathrm{CDCl} 3)$ dos limonoides $1-3$

\begin{tabular}{|c|c|c|c|}
\hline No. & 1 & 2 & 3 \\
\hline 1 & $7,07(\mathrm{~d}, 10,0)$ & $7,09(\mathrm{~d}, 10,0)$ & $3,52(\mathrm{dd}, 6,0 ; 4,0)$ \\
\hline 2 & $5,93(\mathrm{~d}, 10,0)$ & $5,94(\mathrm{~d}, 10,0)$ & $\begin{array}{l}\alpha 2,50(\mathrm{dd}, 14,5 ; 4,0) \\
\beta 2,88(\mathrm{dd}, 14,5 ; 6,0)\end{array}$ \\
\hline 5 & $2,52(\mathrm{~d}, 13,0)$ & $2,17(\mathrm{dd}, 14,0 ; 3,0)$ & $2,86(\mathrm{~d}, 10,0)$ \\
\hline 6 & $\begin{array}{c}5,27(\mathrm{dd}, 13,0 \\
2,5)\end{array}$ & $\begin{array}{c}\alpha 2,41(\mathrm{dd}, 14,0 ; 3,0) \\
\beta 2,92(\mathrm{t}, 14,0)\end{array}$ & $\begin{array}{c}\alpha 2,61(\mathrm{dd}, 16,5 ; 10,0) \\
\beta 2,24(\mathrm{~d}, 16,5)\end{array}$ \\
\hline 7 & $4,89(\mathrm{~d}, 2,5)$ & - & - \\
\hline 9 & $2,53(\mathrm{~d}, 13,0)$ & $2,21(\mathrm{dd}, 10,5 ; 1,5)$ & $2,17(\mathrm{dd}, 5,0 ; 2,0)$ \\
\hline 11 & $\begin{array}{l}1,88(\mathrm{~m}) \\
1,99(\mathrm{~m})\end{array}$ & $\begin{array}{l}1,80(\mathrm{~m}) \\
1,99(\mathrm{~m})\end{array}$ & $\begin{array}{c}1,56(\mathrm{ddd}, 14,0 ; 9,0 ; \\
5,0) \\
2,20(\mathrm{dd}, 15,0 ; 5,0)\end{array}$ \\
\hline 12 & $\begin{array}{l}1,59(\mathrm{~m}) \\
1,74(\mathrm{~m})\end{array}$ & $\begin{array}{l}1,48(\mathrm{~m}) \\
1,84(\mathrm{~m})\end{array}$ & $\begin{array}{c}1,12(\mathrm{dd}, 14,0 ; 5,0) \\
1,89(\mathrm{ddd}, 14,0 ; 14,0 ; \\
5,0)\end{array}$ \\
\hline 15 & $3,61(\mathrm{~s})$ & $3,86(\mathrm{~s})$ & $\begin{array}{l}2,57(\mathrm{~d}, 18,0) \\
2,91(\mathrm{~d} 18,0)\end{array}$ \\
\hline 17 & $5,61(\mathrm{~s})$ & $5,46(\mathrm{~s})$ & $5,66(\mathrm{~s})$ \\
\hline 18 & $1,24(\mathrm{~s})$ & $1,13(\mathrm{~s})$ & $0,86(\mathrm{~s})$ \\
\hline 19 & $1,20(s)$ & $1,35(\mathrm{~s})$ & $0,94(s)$ \\
\hline 21 & $7,41(\mathrm{dl}, 1,0)$ & $7,41(\mathrm{dl}, 1,0)$ & 7,43(sl) \\
\hline 22 & $6,33(\mathrm{t}, 1,5)$ & $6,36(\mathrm{dl}, 1,5)$ & $6,38(\mathrm{dl}, 1,0)$ \\
\hline 23 & $7,41(\mathrm{dl}, 1,0)$ & $7,39(\mathrm{t}, 1,5)$ & $7,38(\mathrm{t}, 1,0)$ \\
\hline 28 & $1,25(\mathrm{~s})$ & $1,15(\mathrm{~s})$ & $1,04(\mathrm{~s})$ \\
\hline 29 & $1,16(\mathrm{~s})$ & $1,12(\mathrm{~s})$ & $1,19(\mathrm{~s})$ \\
\hline 30 & $1,27(s)$ & $1,21(\mathrm{~s})$ & $4,89(\mathrm{~s}) ; 5,19(\mathrm{~s})$ \\
\hline $6-\mathrm{OCOC}_{3}$ & $2,03(\mathrm{~s})$ & - & - \\
\hline 7- $\mathrm{OCOC} \underline{H}_{3}$ & $2,15(\mathrm{~s})$ & - & - \\
\hline $\mathrm{OCH}_{3}$ & - & - & $3,71(\mathrm{~s})$ \\
\hline
\end{tabular}




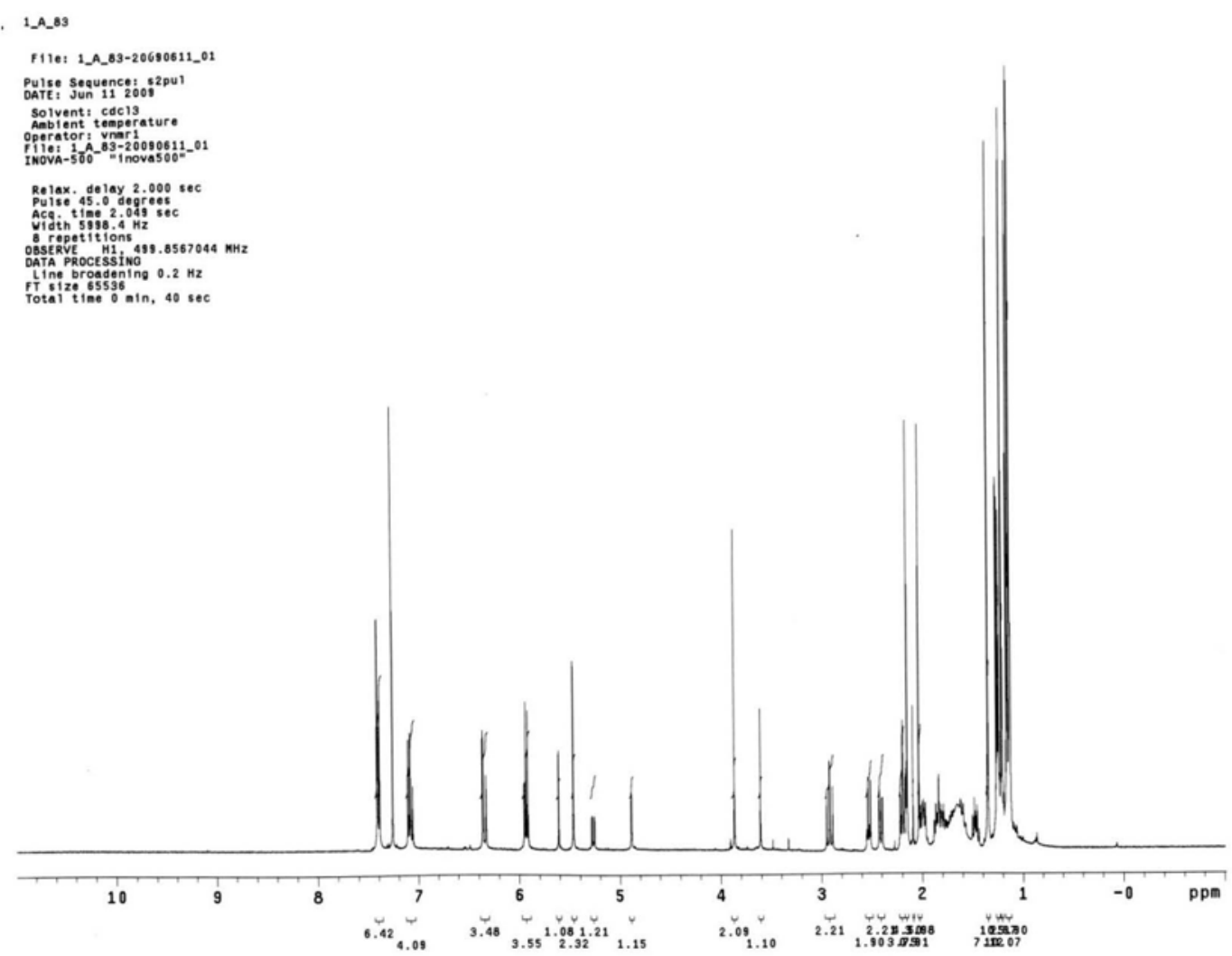

Figura 1S. Espectro de $R M N^{l} H$ da mistura dos limonoides $6 \alpha$-acetoxigedunina e 7-desacetil-7oxogedunina (1 e 2)
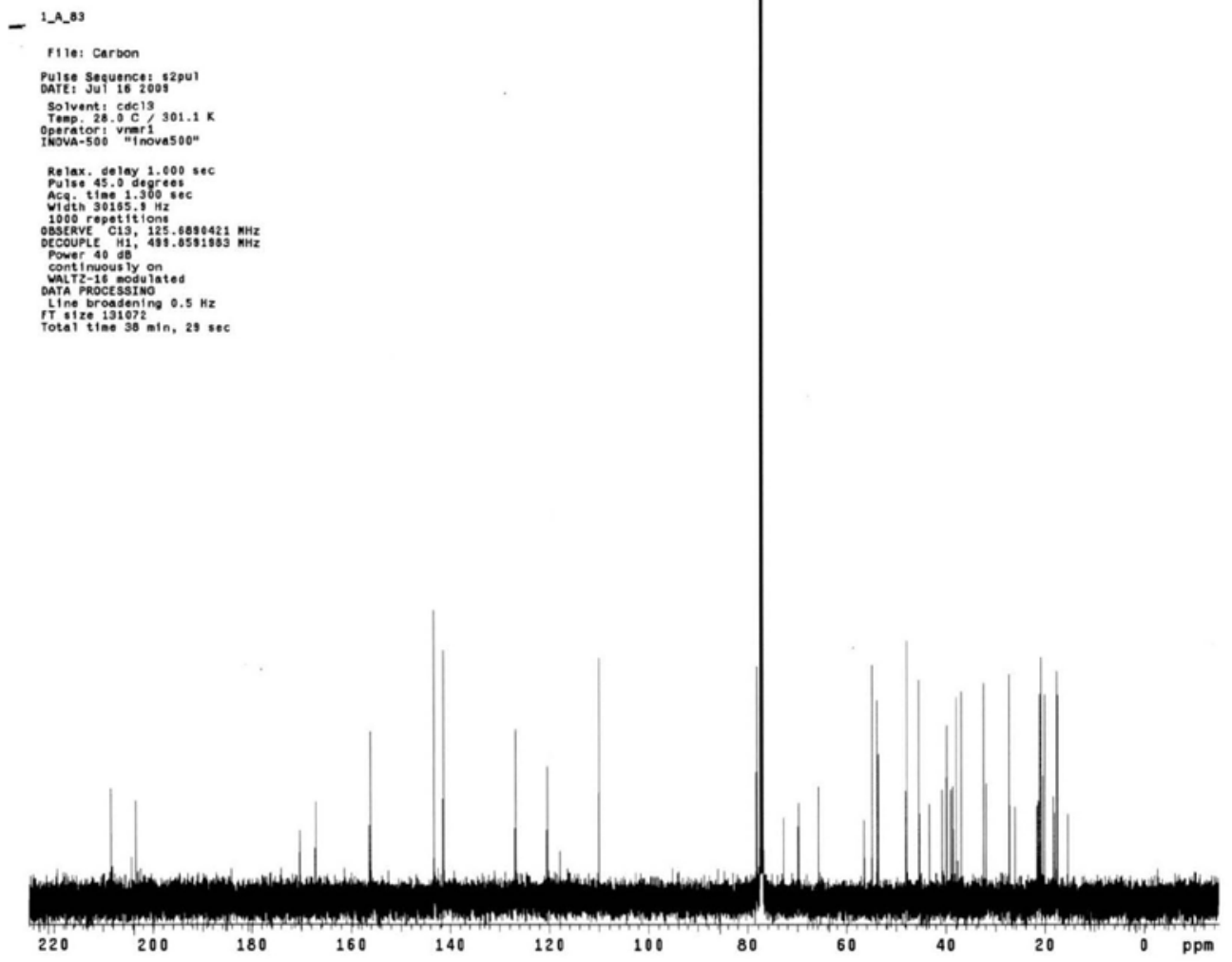

Figura 2S. Espectro de $R M N{ }^{13} \mathrm{C}$ da mistura dos limonoides $6 \alpha$-acetoxigedunina e 7-desacetil-7oxogedunina (1 e 2) 

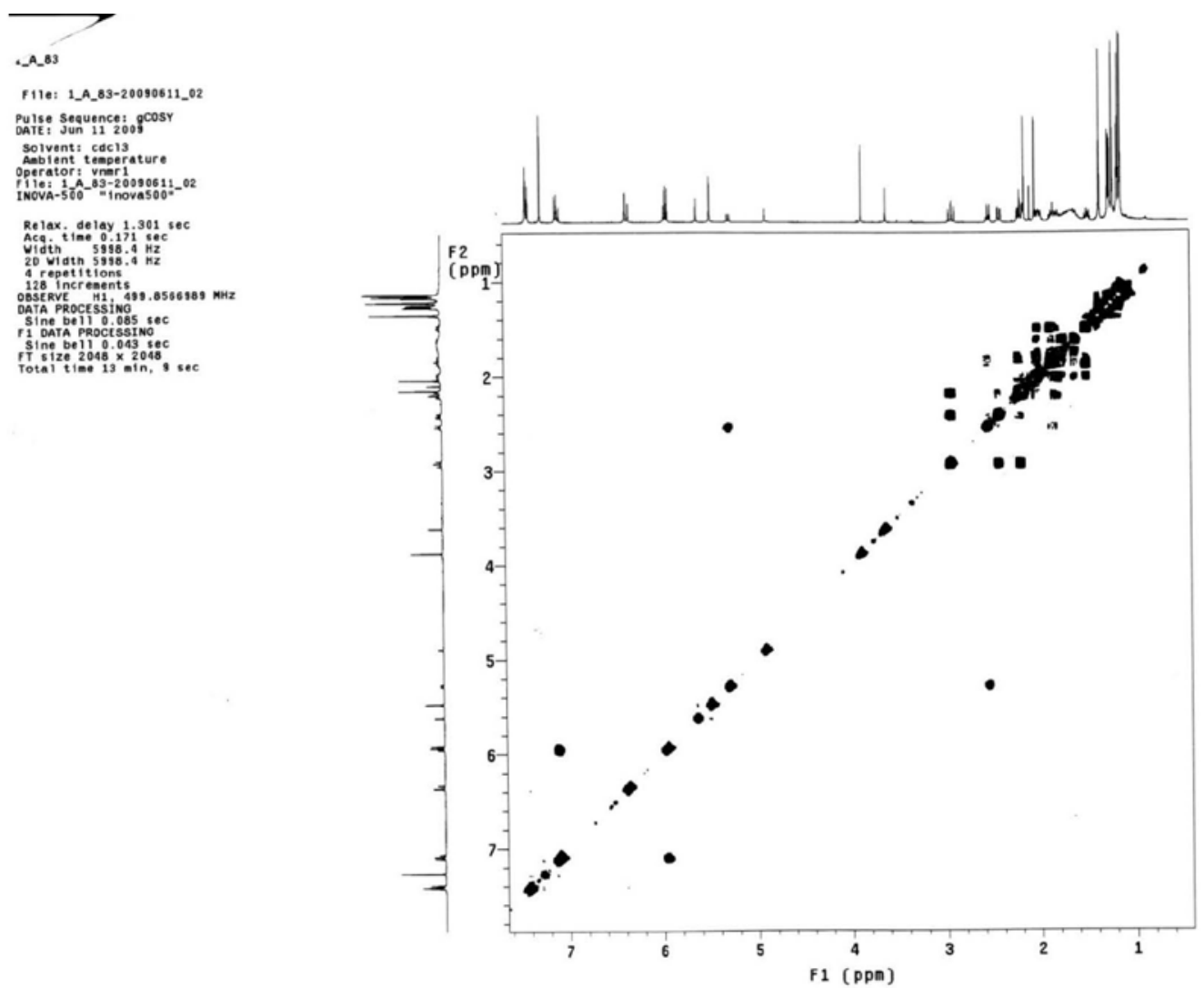

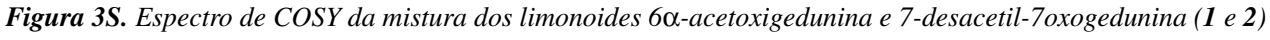

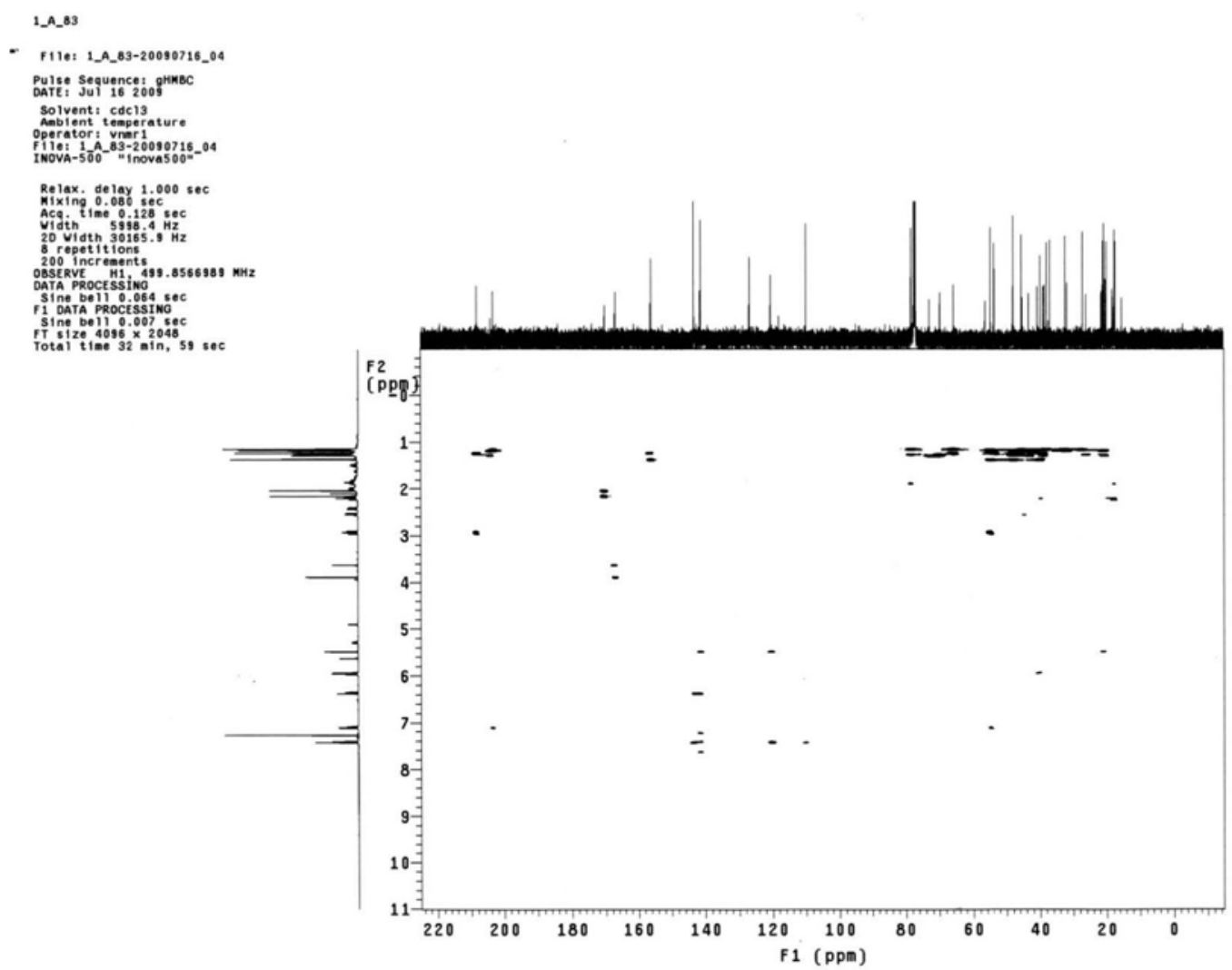

Figura 4S. Espectro de HMBC da mistura dos limonoides 6 $\alpha$-acetoxigedunina e 7-desacetil-7oxogedunina (1 e 2) 


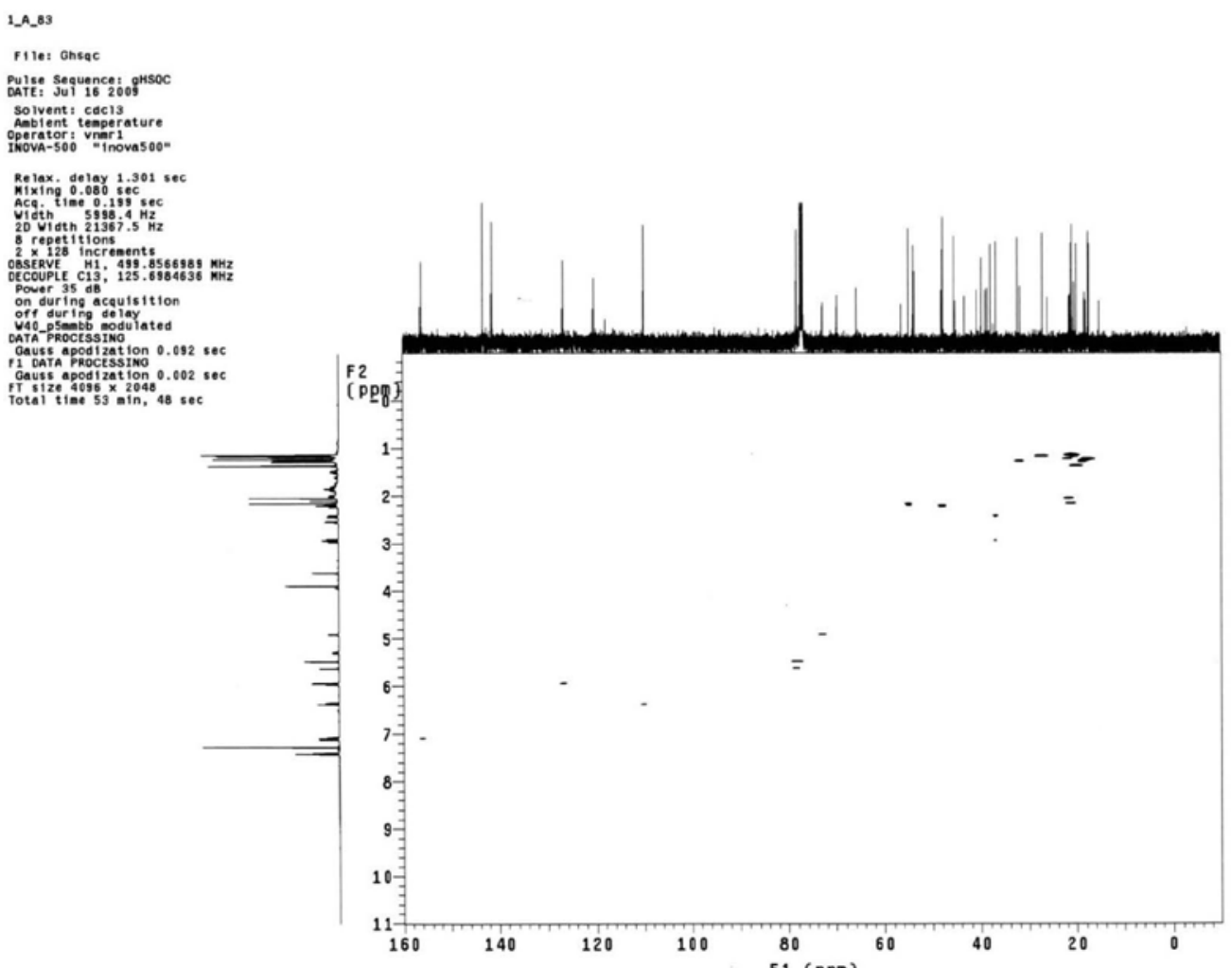

Figura 5S. Espectro de HSQC da mistura dos limonoides 6 $\alpha$-acetoxigedunina e 7-desacetil-7oxogedunina (1 e 2)
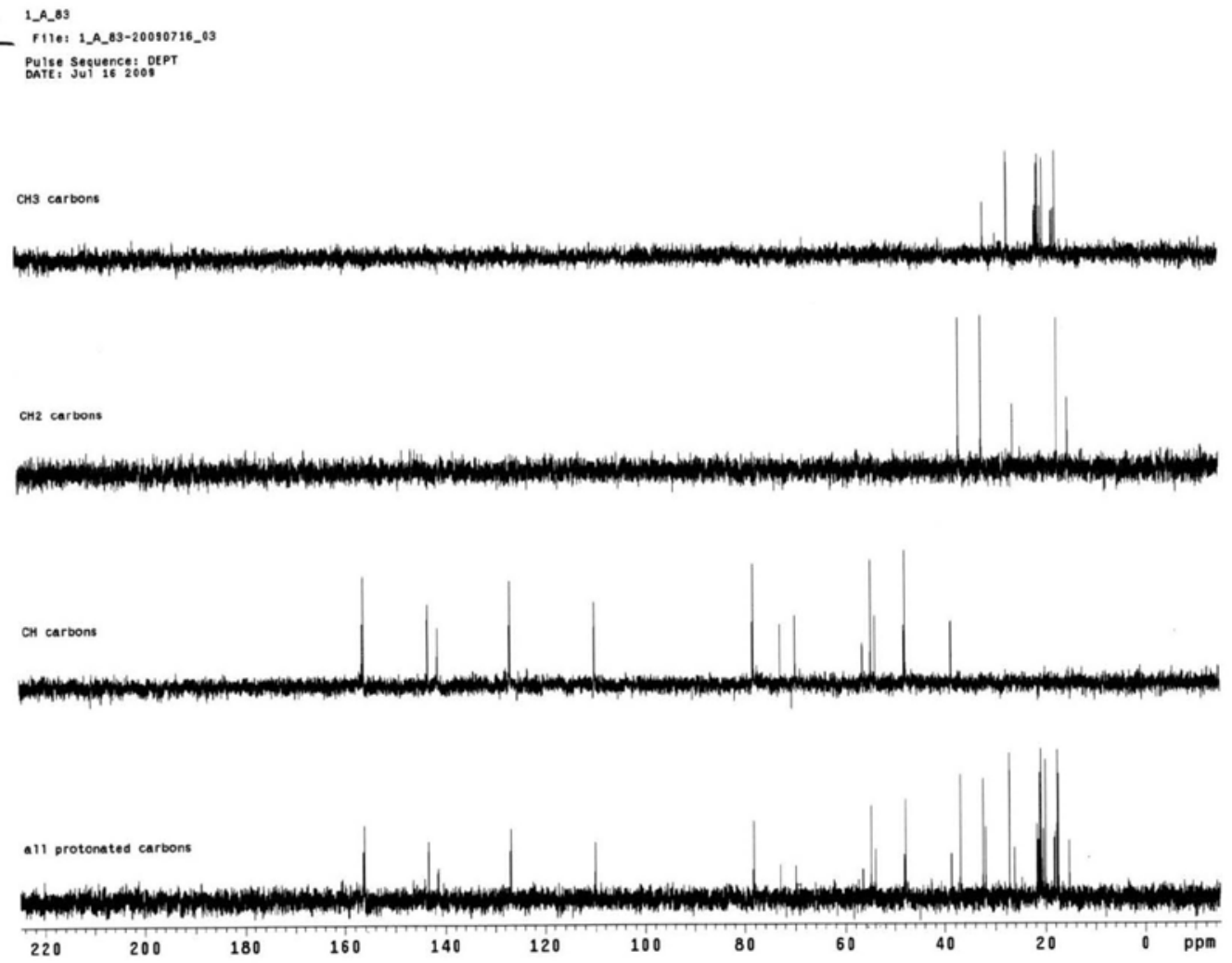

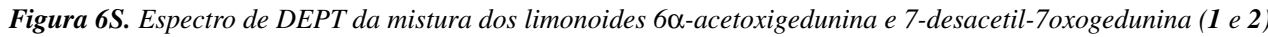




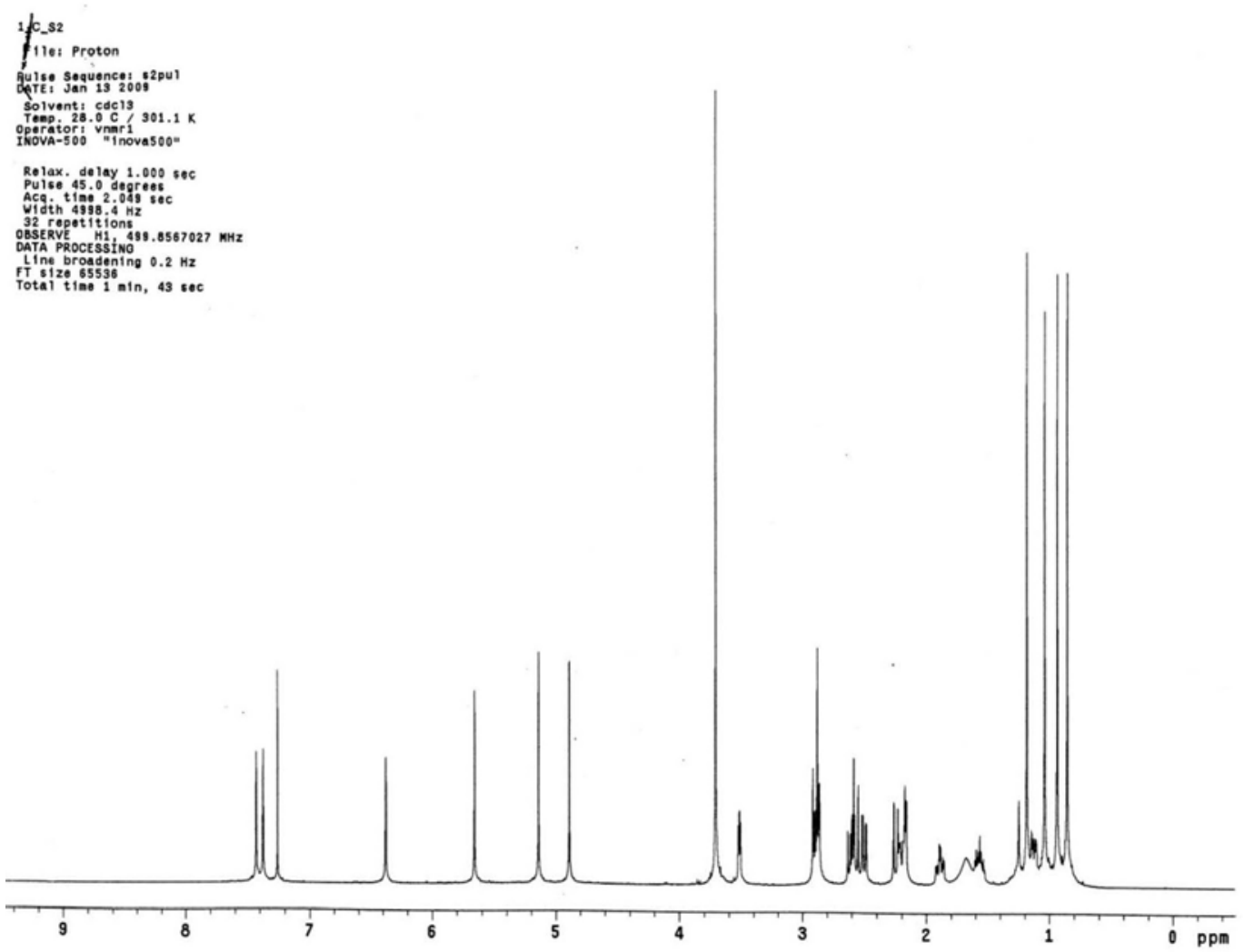

Figura 7S. Espectro de $R M N^{1} \mathrm{H}$ do limonoide angolensato de metila (3)

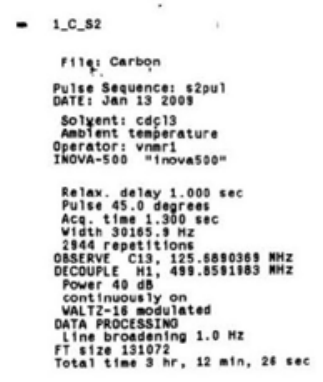

Aley carbọn

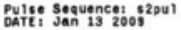

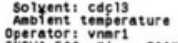

ilax. delay 1.000 sec

.

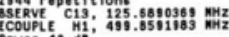

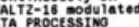

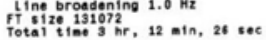

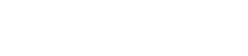



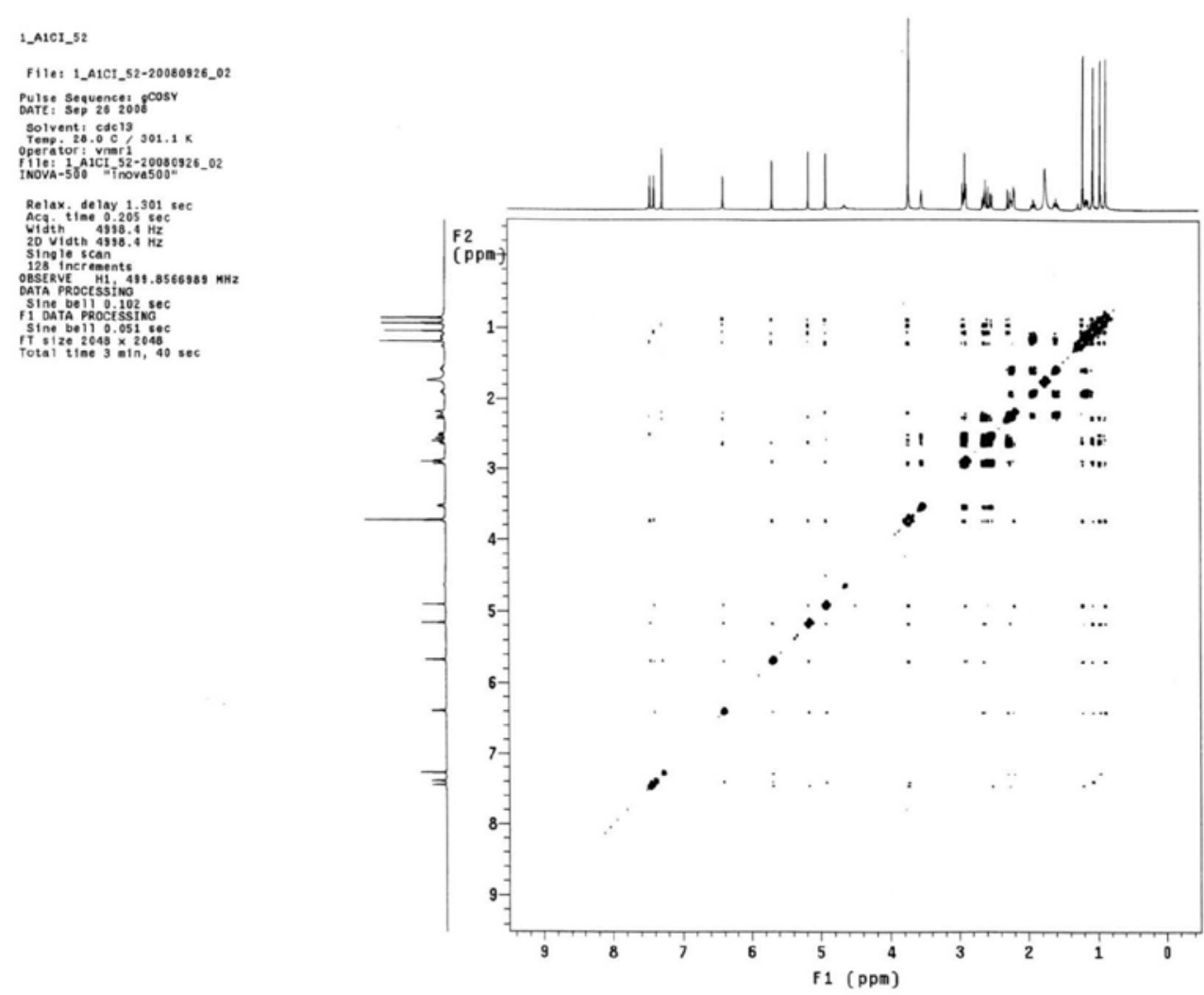

Figura 9S. Espectro de COSY do limonoide angolensato de metila (3)
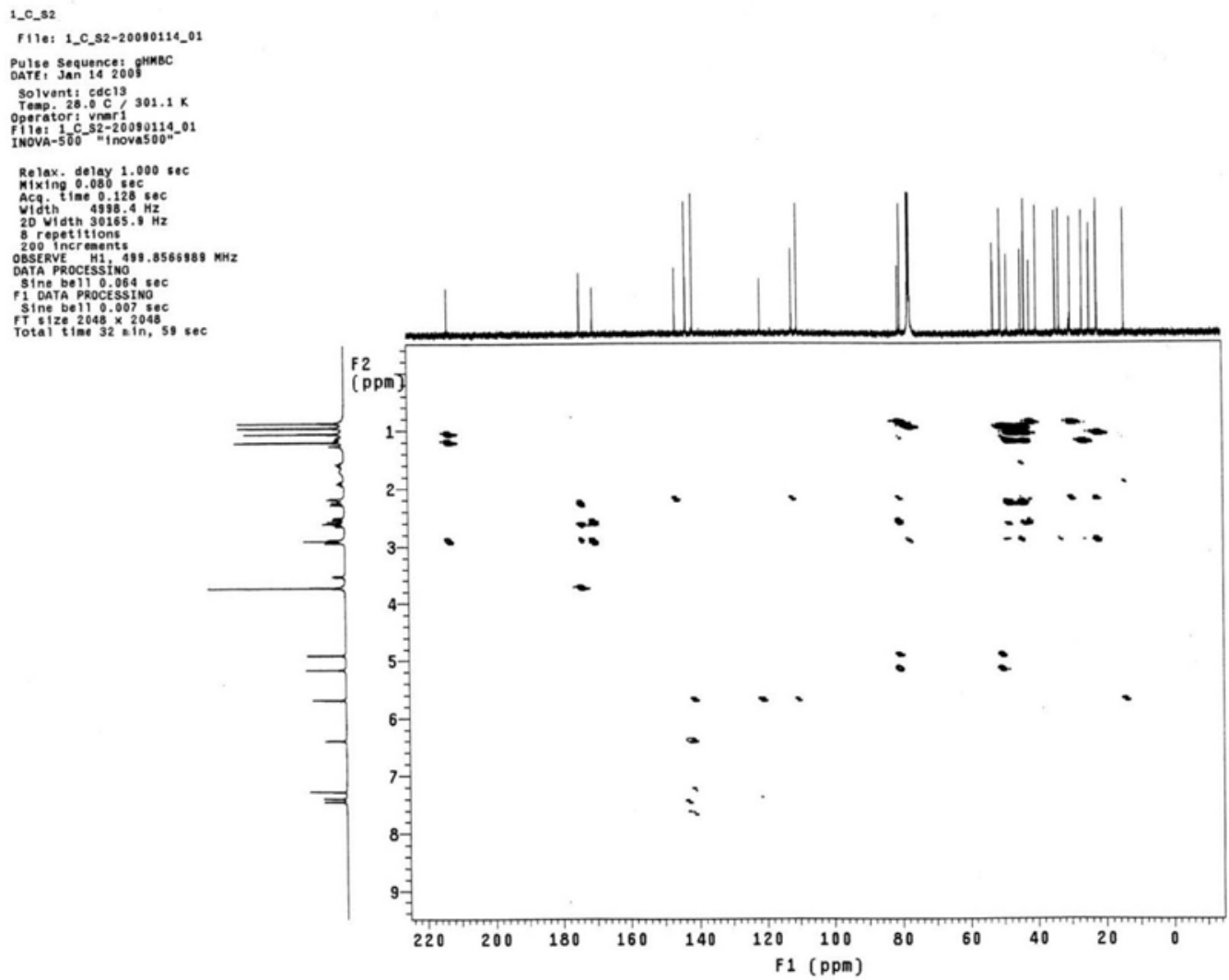

Figura 10S. Espectro de HMBC do limonoide angolensato de metila (3) 


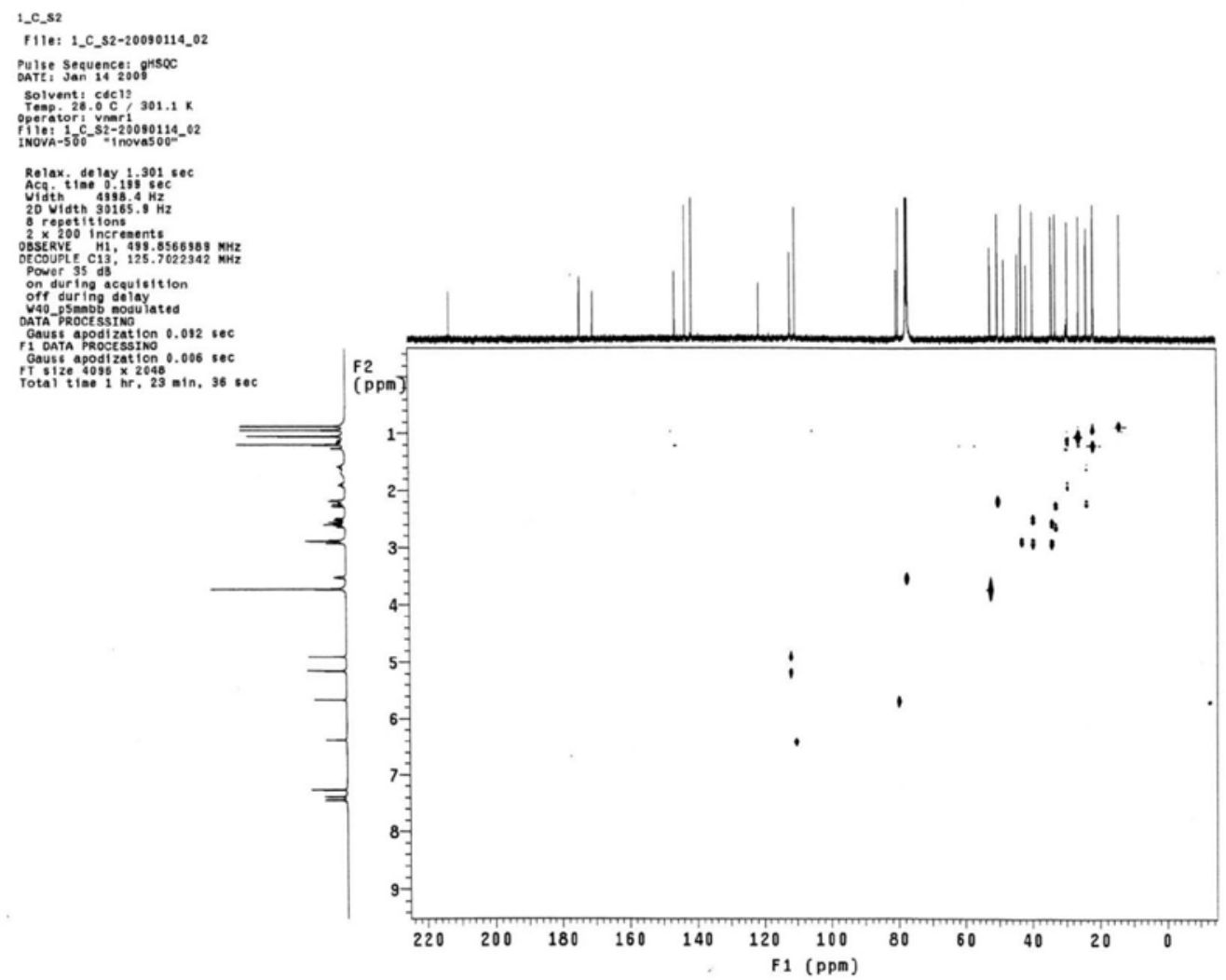

Figura 11S. Espectro de HSQC do limonoide angolensato de metila (3)
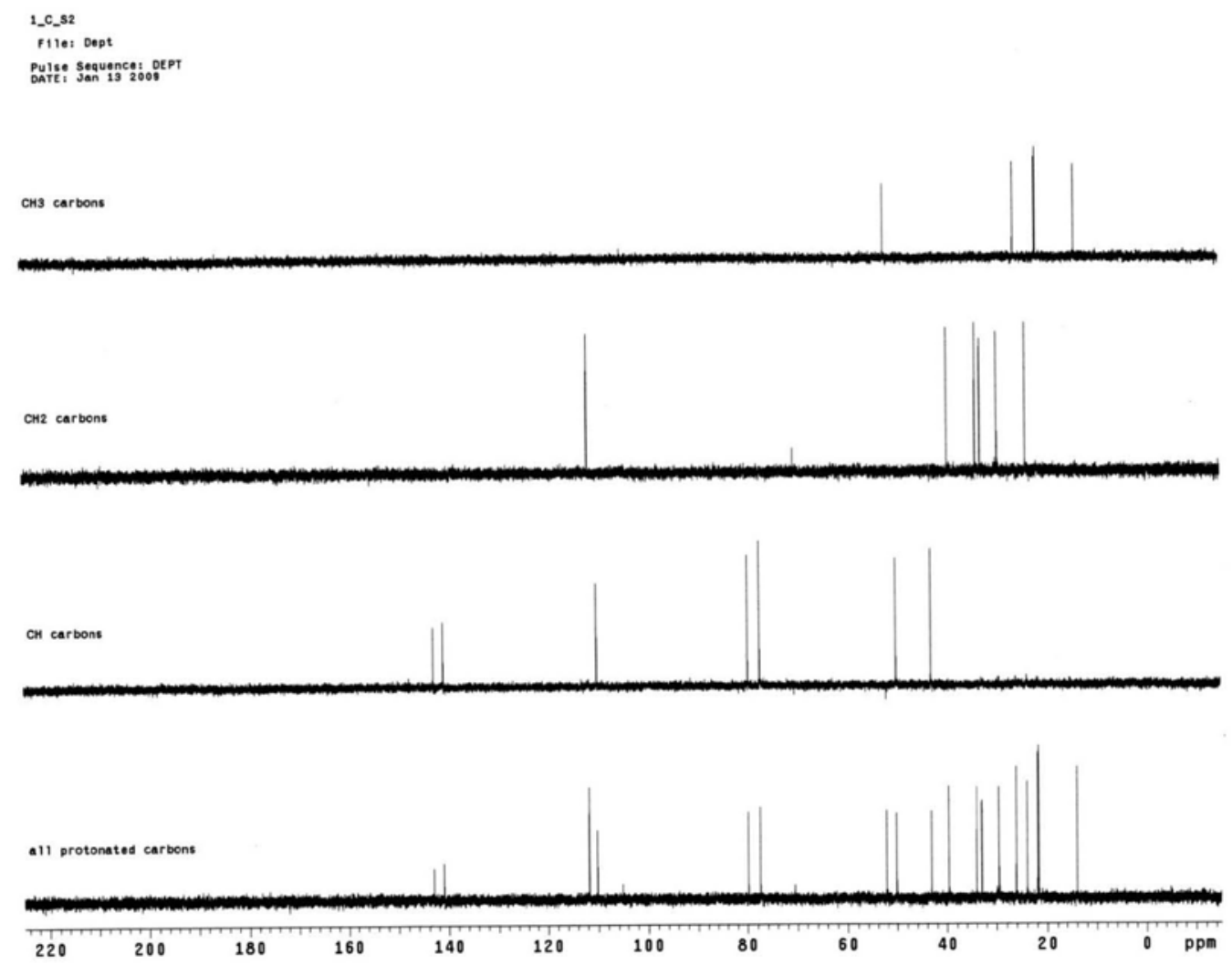

Figura 12S. Espectro de DEPT do limonoide angolensato de metila (3) 


\section{$\dot{1}_{0.32}$}

F110: proton

Rulte: Seguence: 15 ispul

Solventic.cecc13 301.1

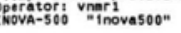

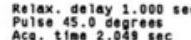

Acg int ${ }^{2}$

Oosservet titions $49.0567033 \mathrm{kHz}$

OATA PRocessiso $0.2 \mathrm{~Hz}$

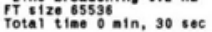

.

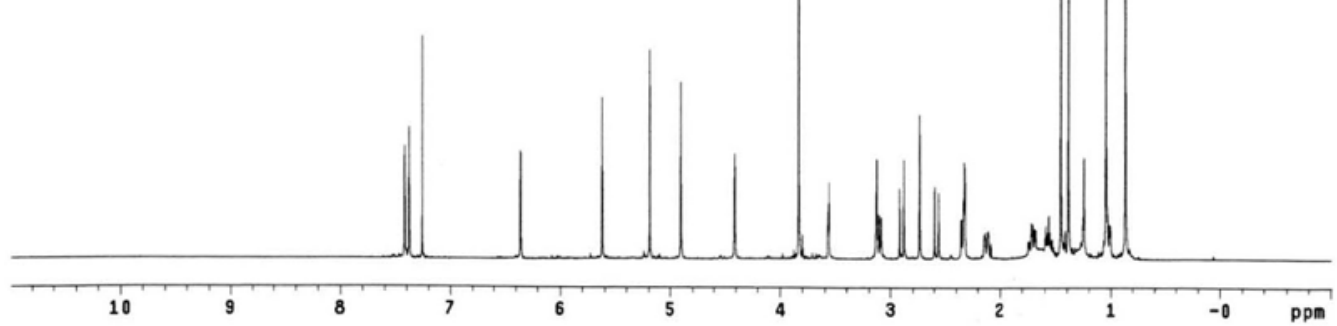

Figura 13S. Espectro de $R M N^{l} H$ do limonoide 6hidroxi-angolensato de metila (4)

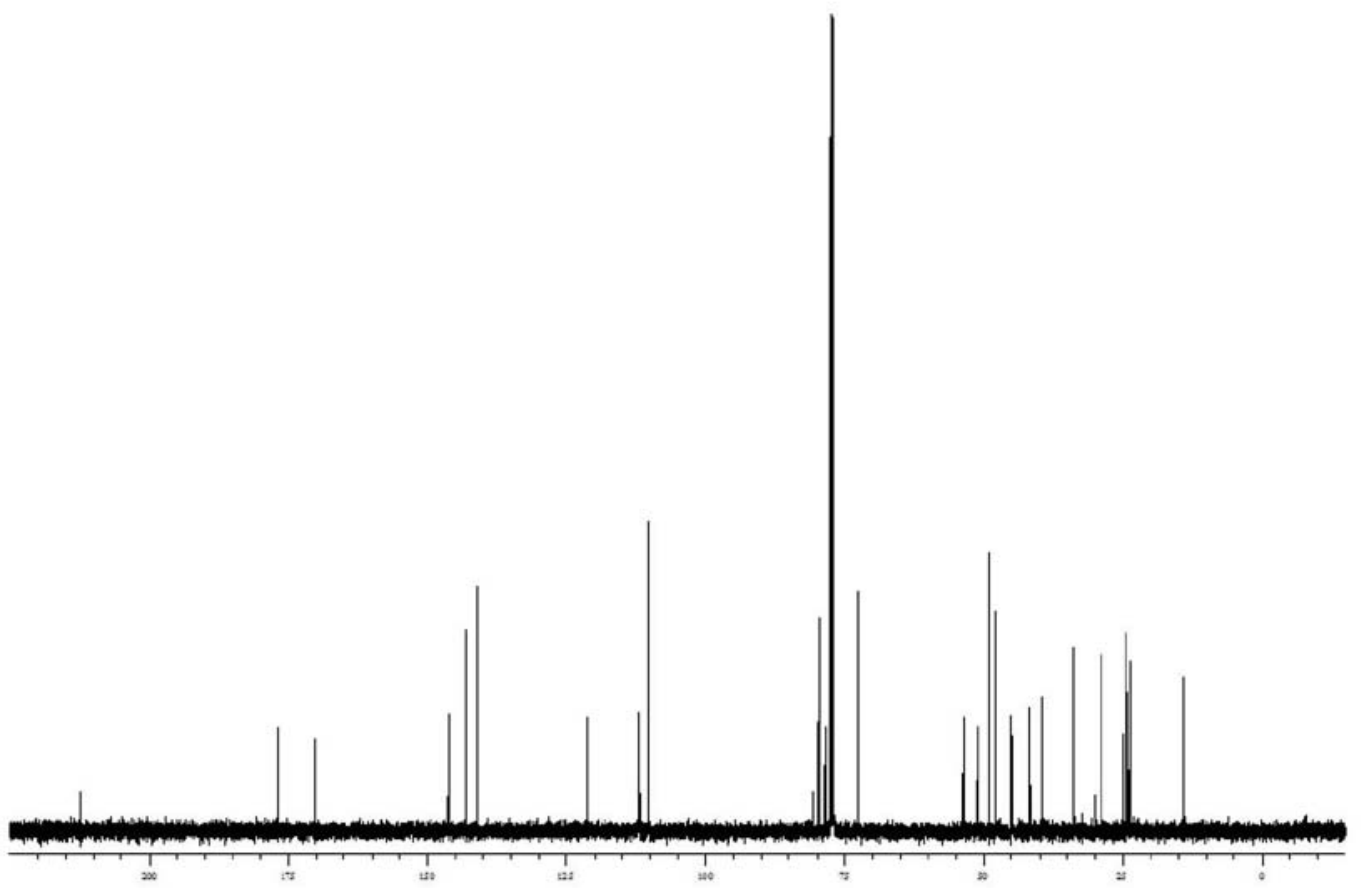

Figura 14S. Espectro de $R M N^{13} \mathrm{C}$ do limonoide 6hidroxi-angolensato de metila (4) 

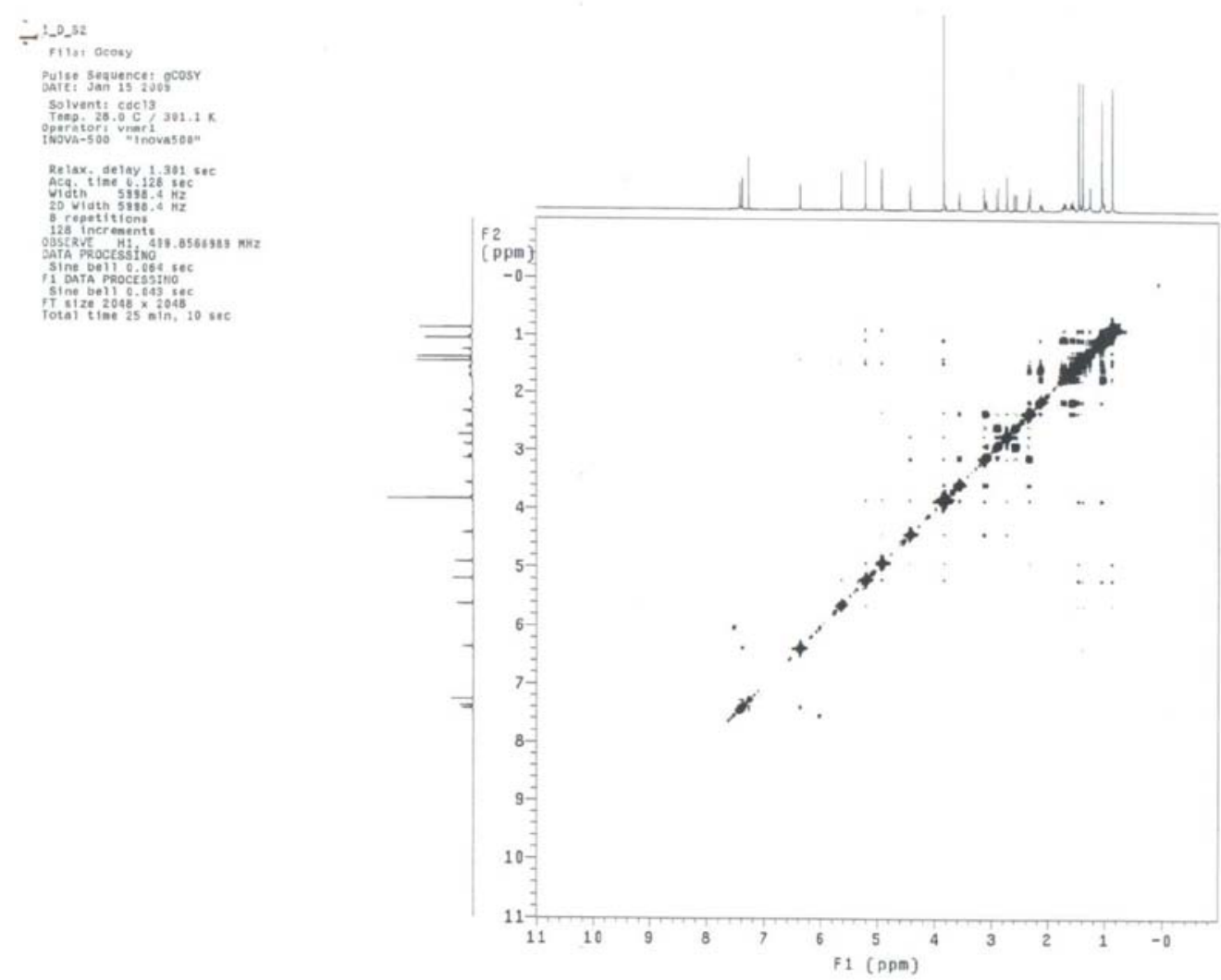

Figura 15S. Espectro de COSY do limonoide 6hidroxi-angolensato de metila (4)

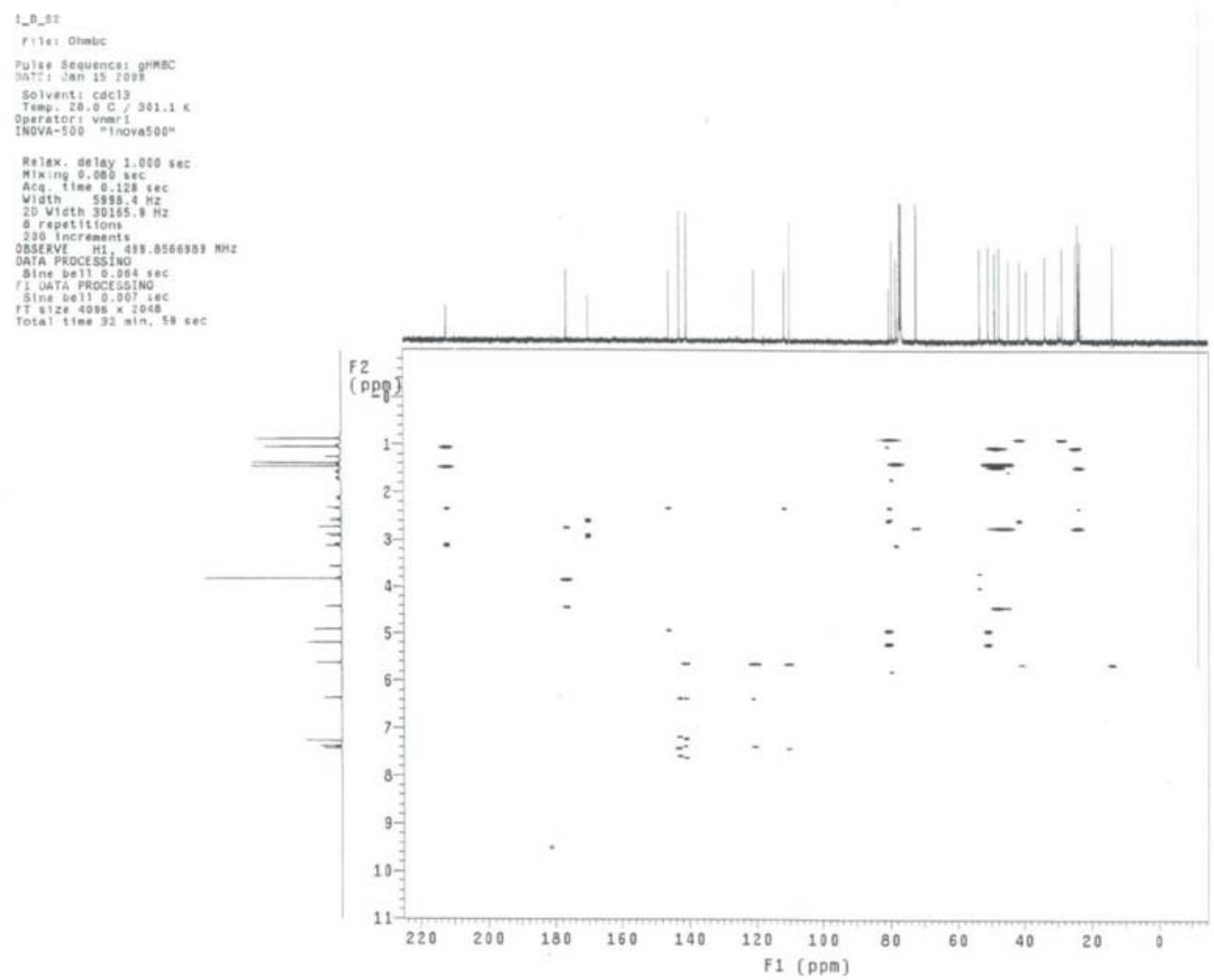

Figura 16S. Espectro de HMBC do limonoide 6hidroxi-angolensato de metila (4) 
$1,0.3:$

Hile: ansed

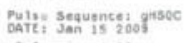

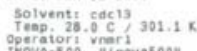
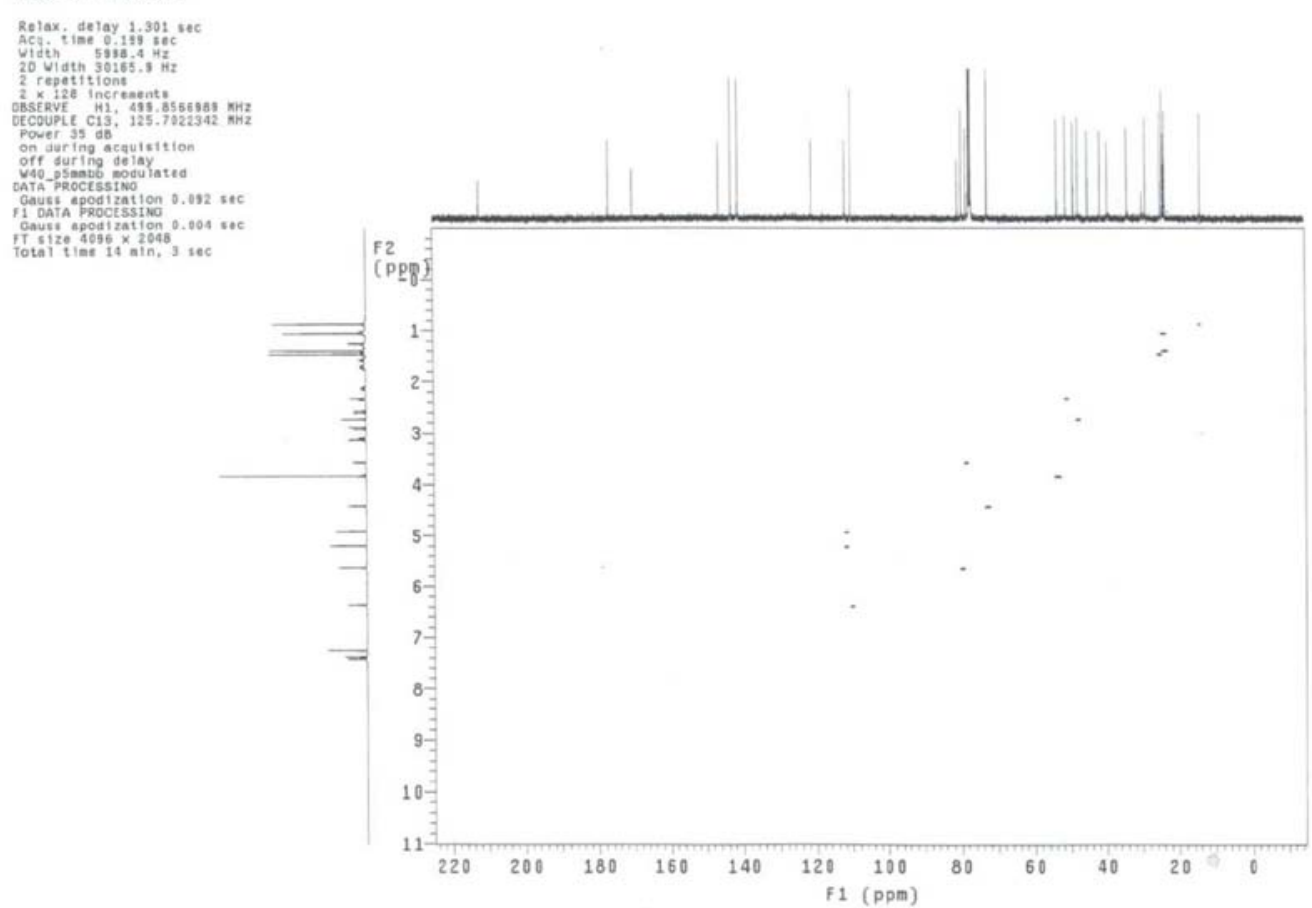

Figura 17S. Espectro de HSQC do limonoide 6hidroxi-angolensato de metila (4)
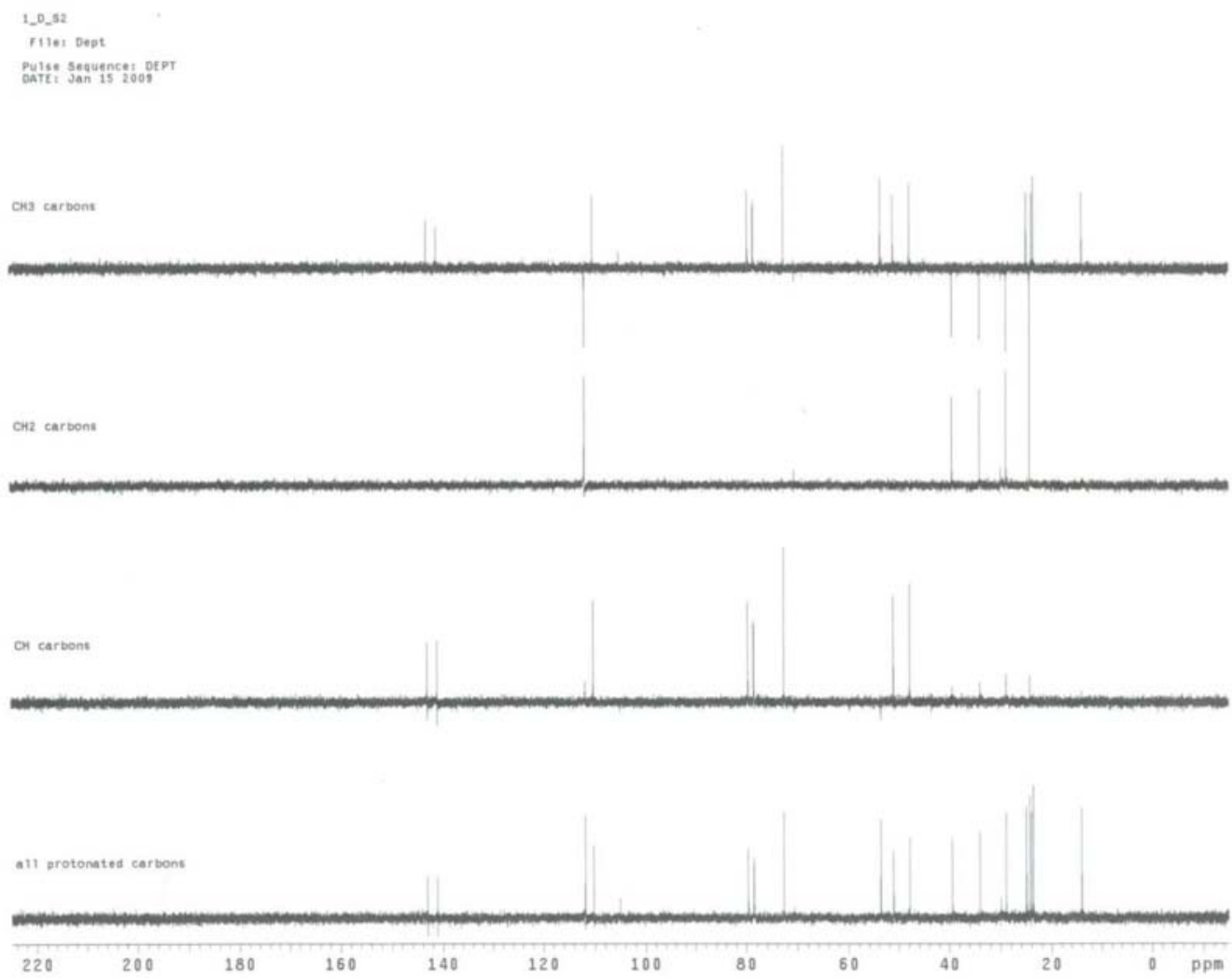

Figura 18S. Espectro de DEPT do limonoide 6hidroxi-angolensato de metila (4) 

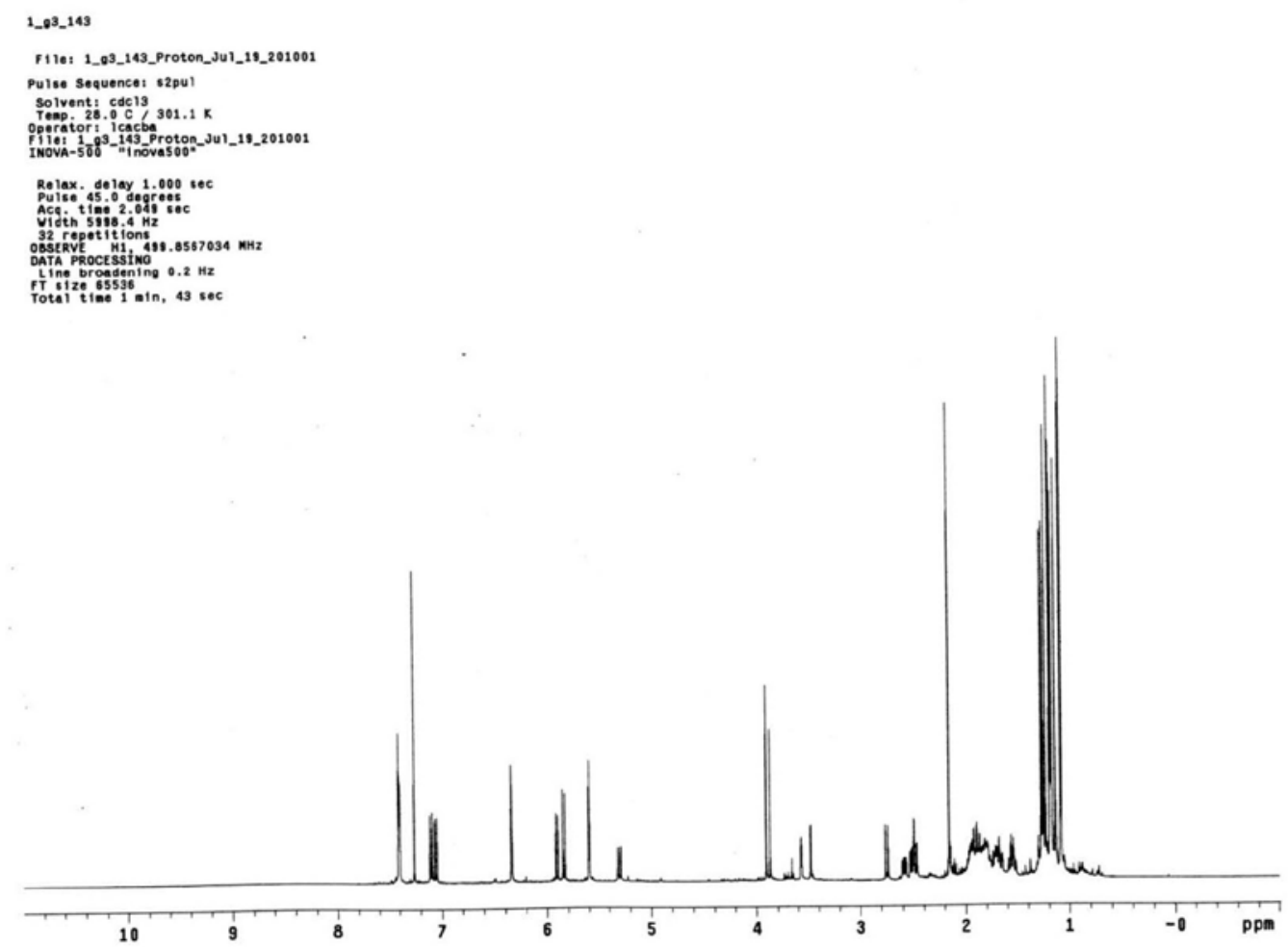

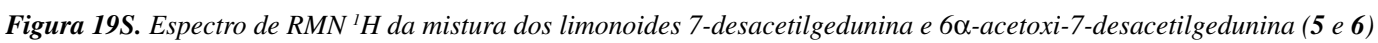

$$
\text { std proton }
$$

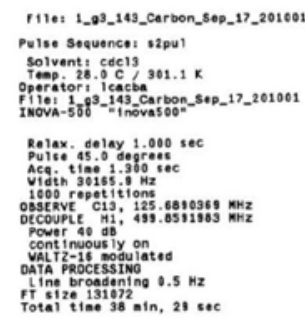

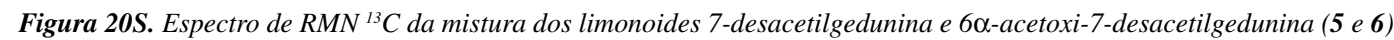



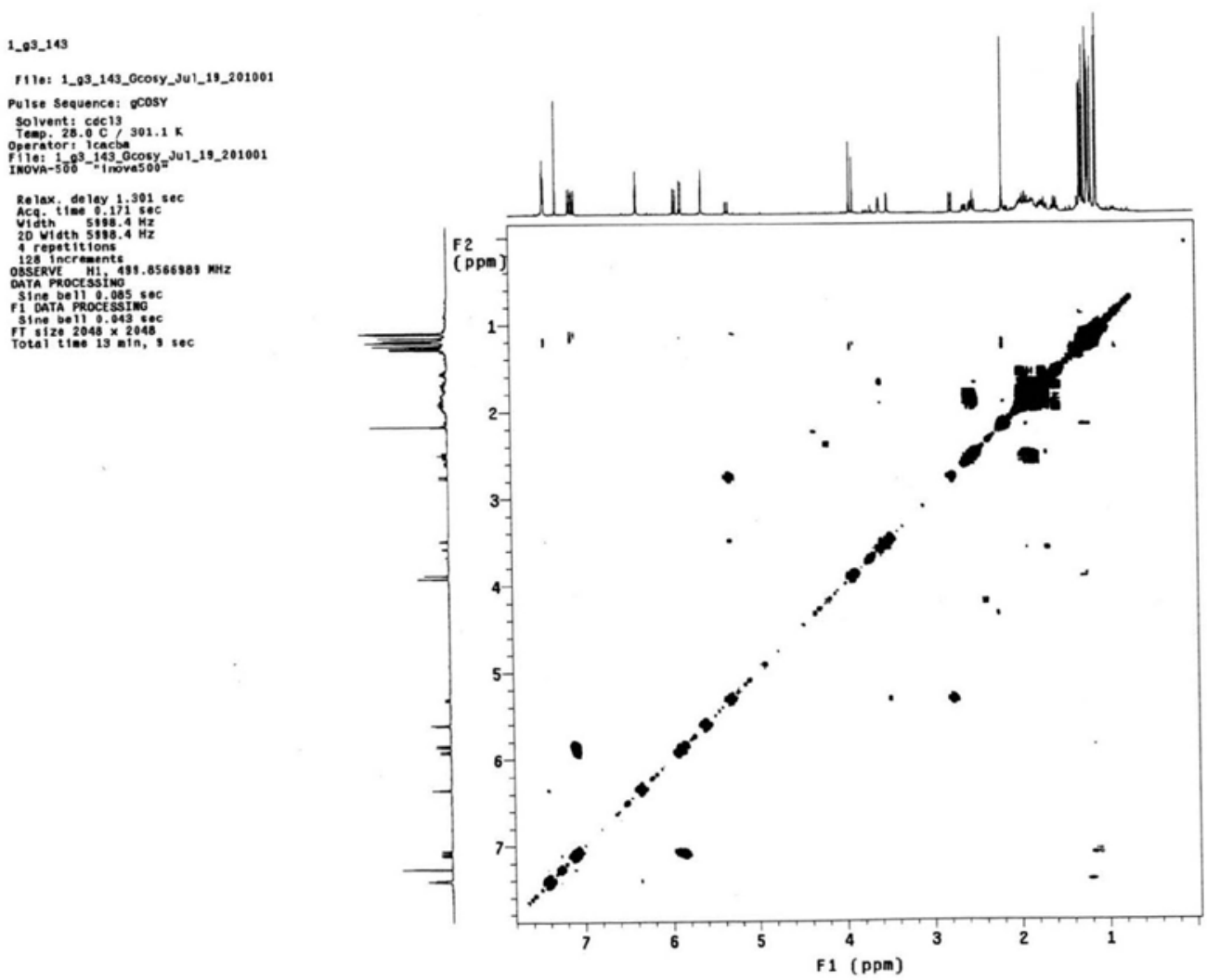

Figura 21S. Espectro de COSY da mistura dos limonoides 7-desacetilgedunina e 6 -acetoxi-7-desacetilgedunina (5 e 6)

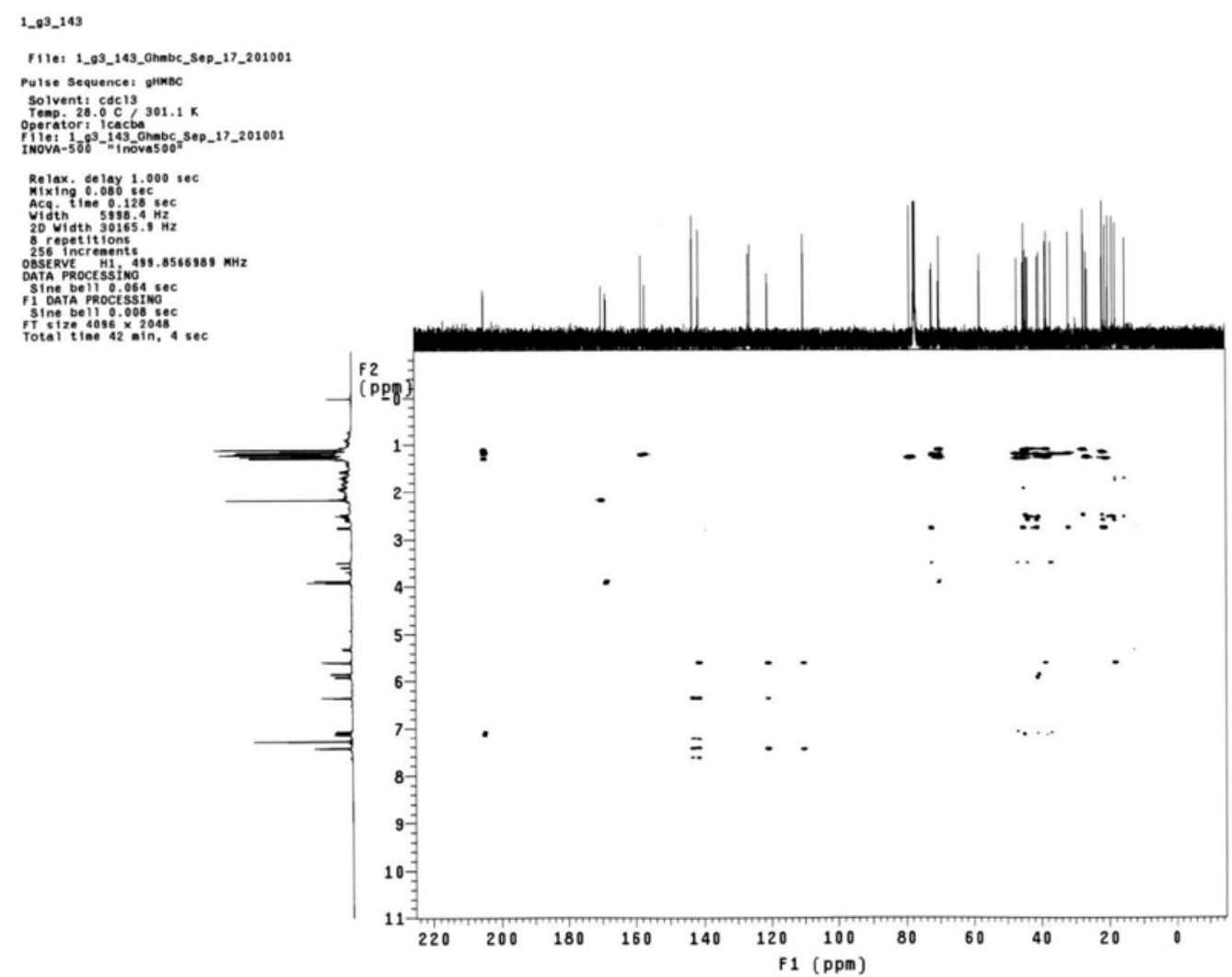

Figura 22S. Espectro de HMBC da mistura dos limonoides 7-desacetilgedunina e 6 -acetoxi-7-desacetilgedunina (5 e 6) 


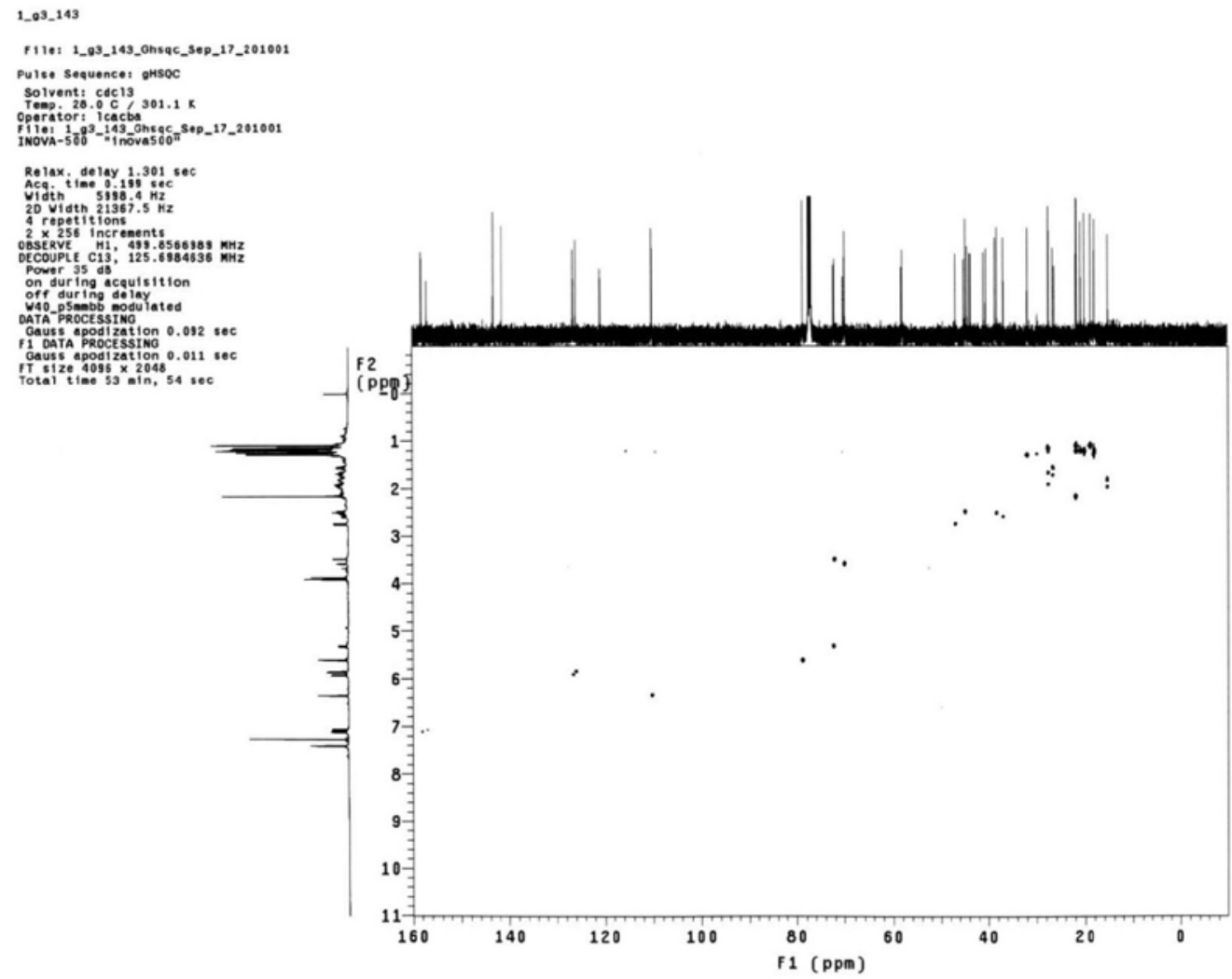

Figura 23S. Espectro de HSQC da mistura dos limonoides 7-desacetilgedunina e 6 -acetoxi-7-desacetilgedunina (5 e 6 )

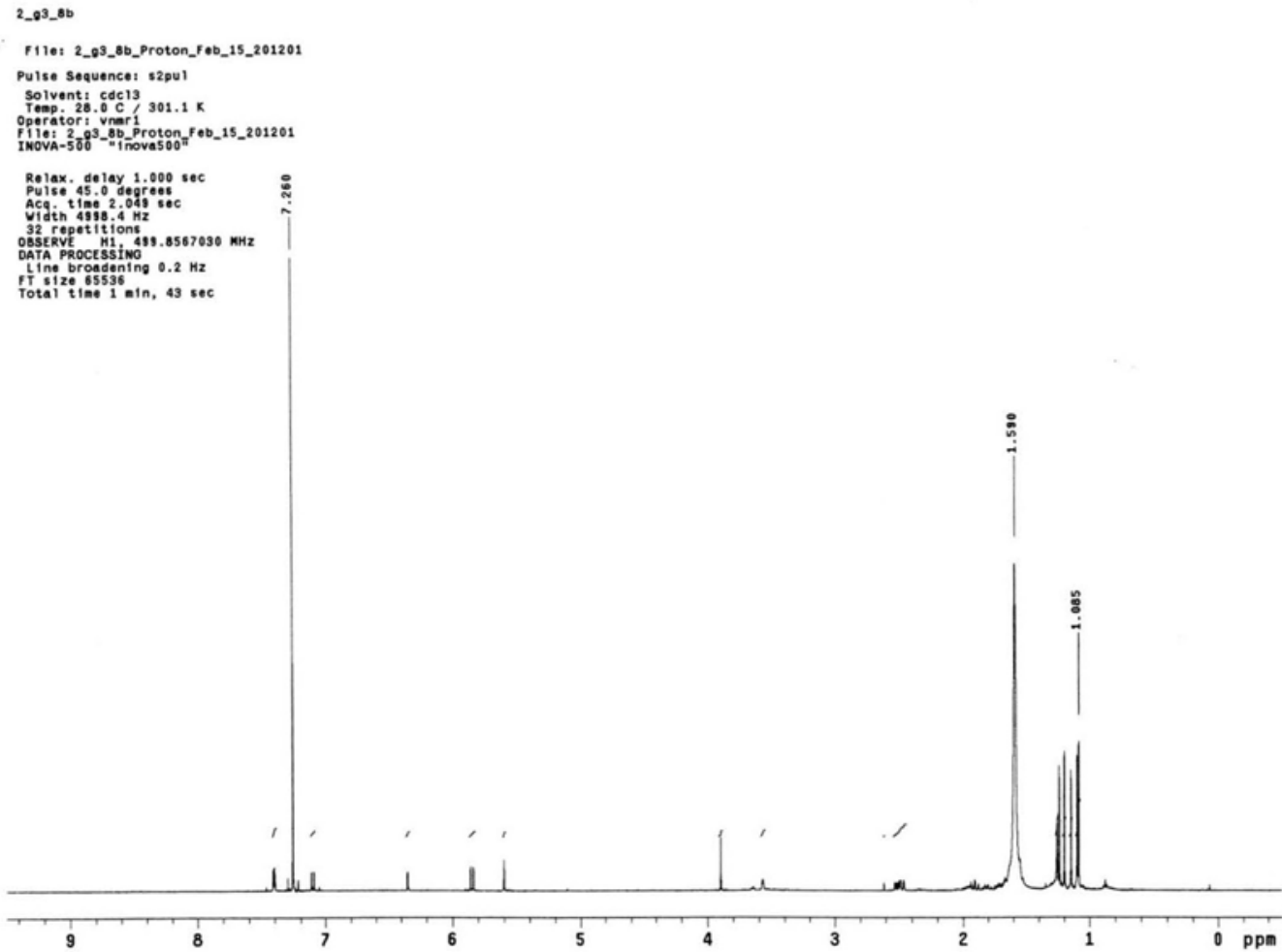

Figura 24S. Espectro de $R M N^{1} H$ do limonoide 7-desacetilgedunina (5) 

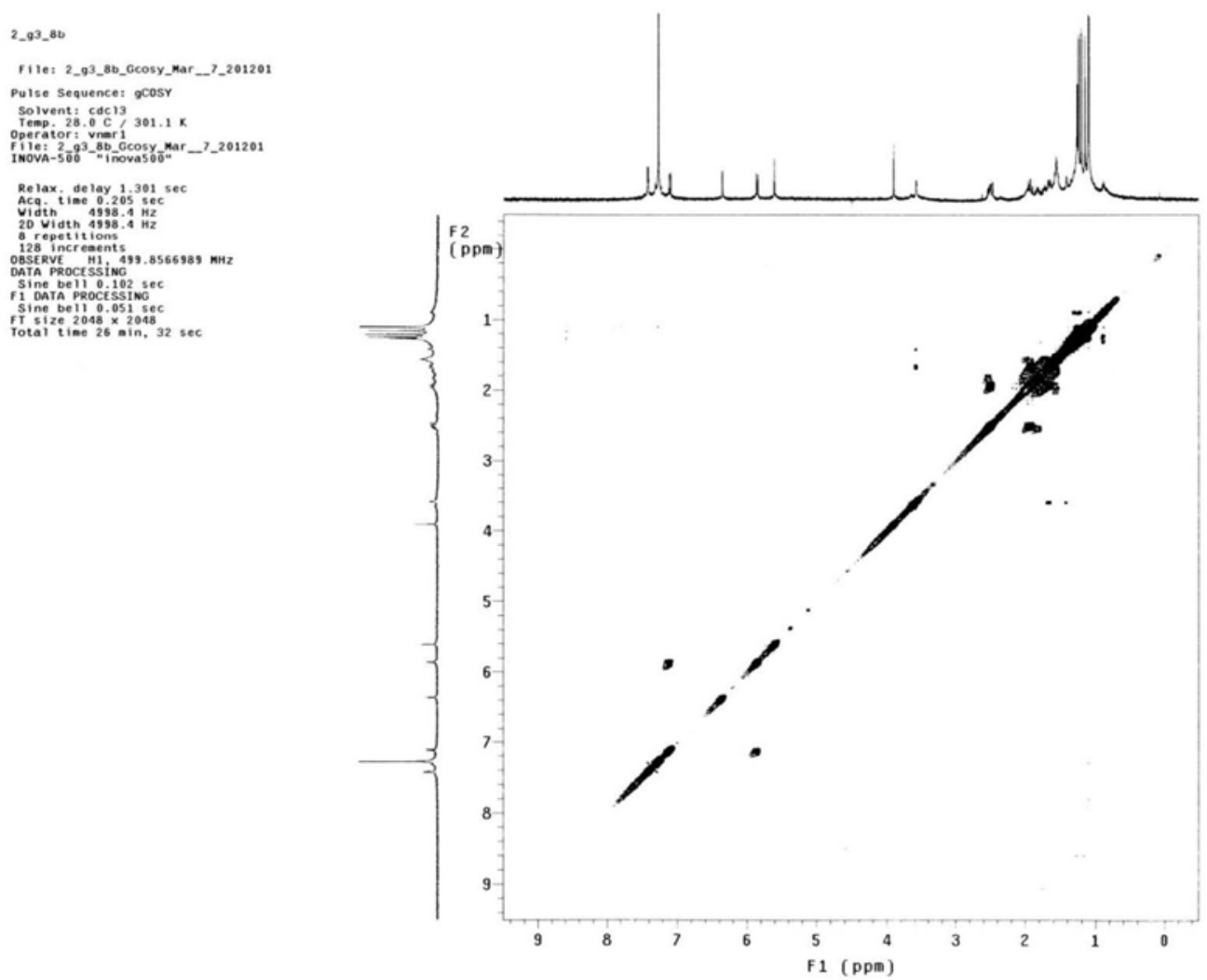

Figura 25S. Espectro de COSY do limonoide 7-desacetilgedunina (5)

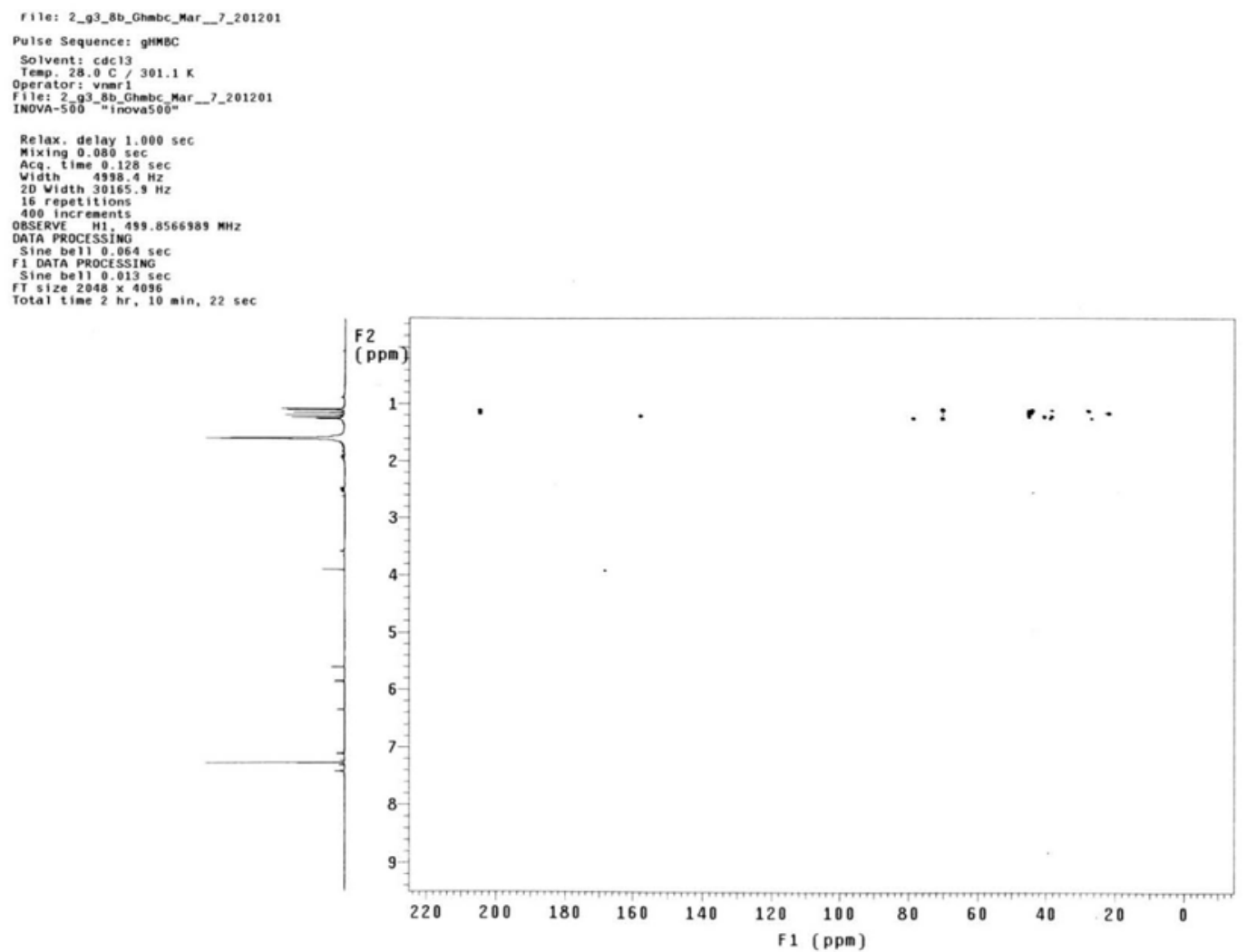

Figura 26S. Espectro de HMBC do limonoide 7-desacetilgedunina (5) 


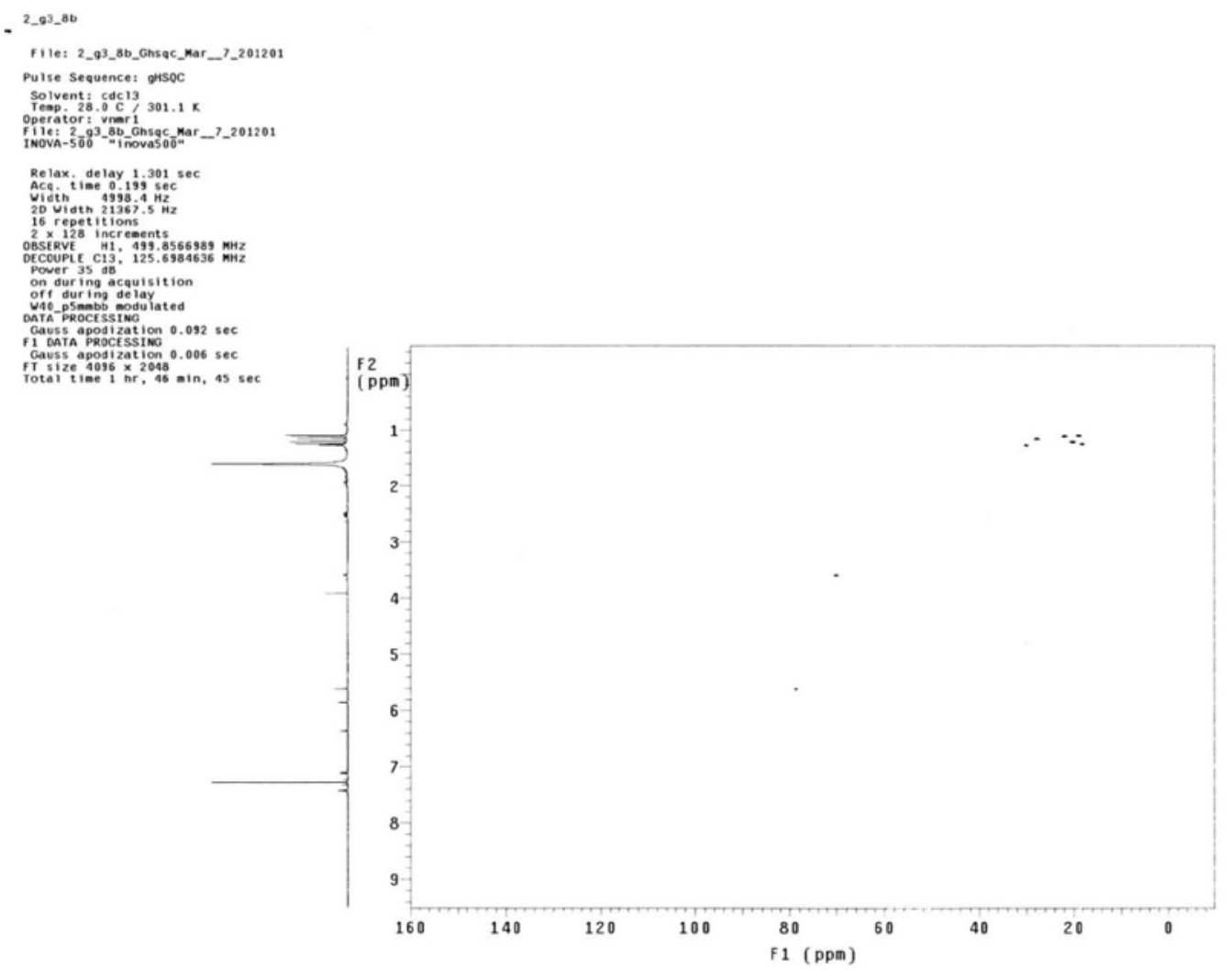

Figura 27S. Espectro de HSQC do limonoide 7-desacetilgedunina (5)

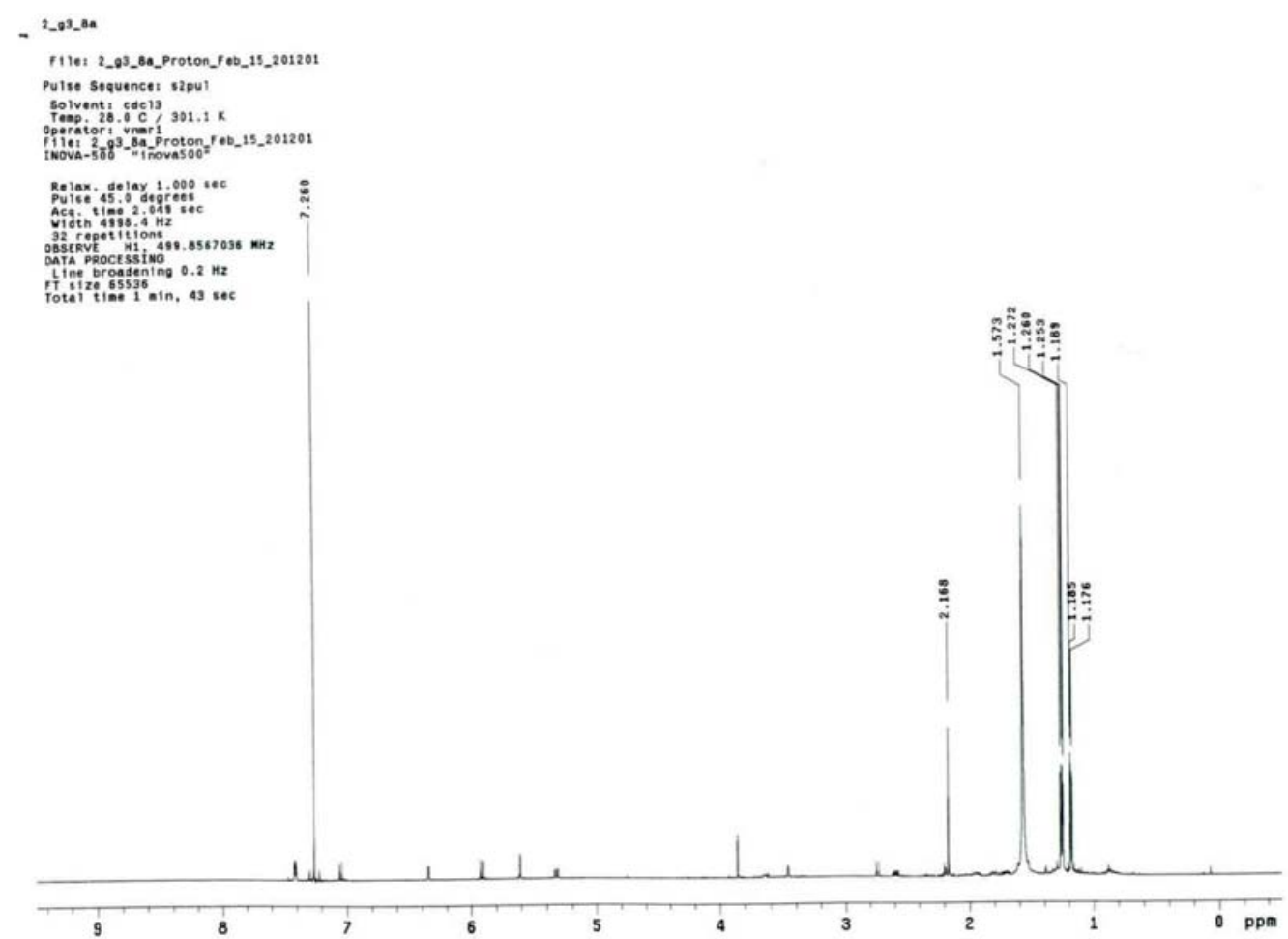

Figura 28S. Espectro de $R M N^{l} H$ do limonoide $6 \alpha$-acetoxi-7-desacetilgedunina (6) 

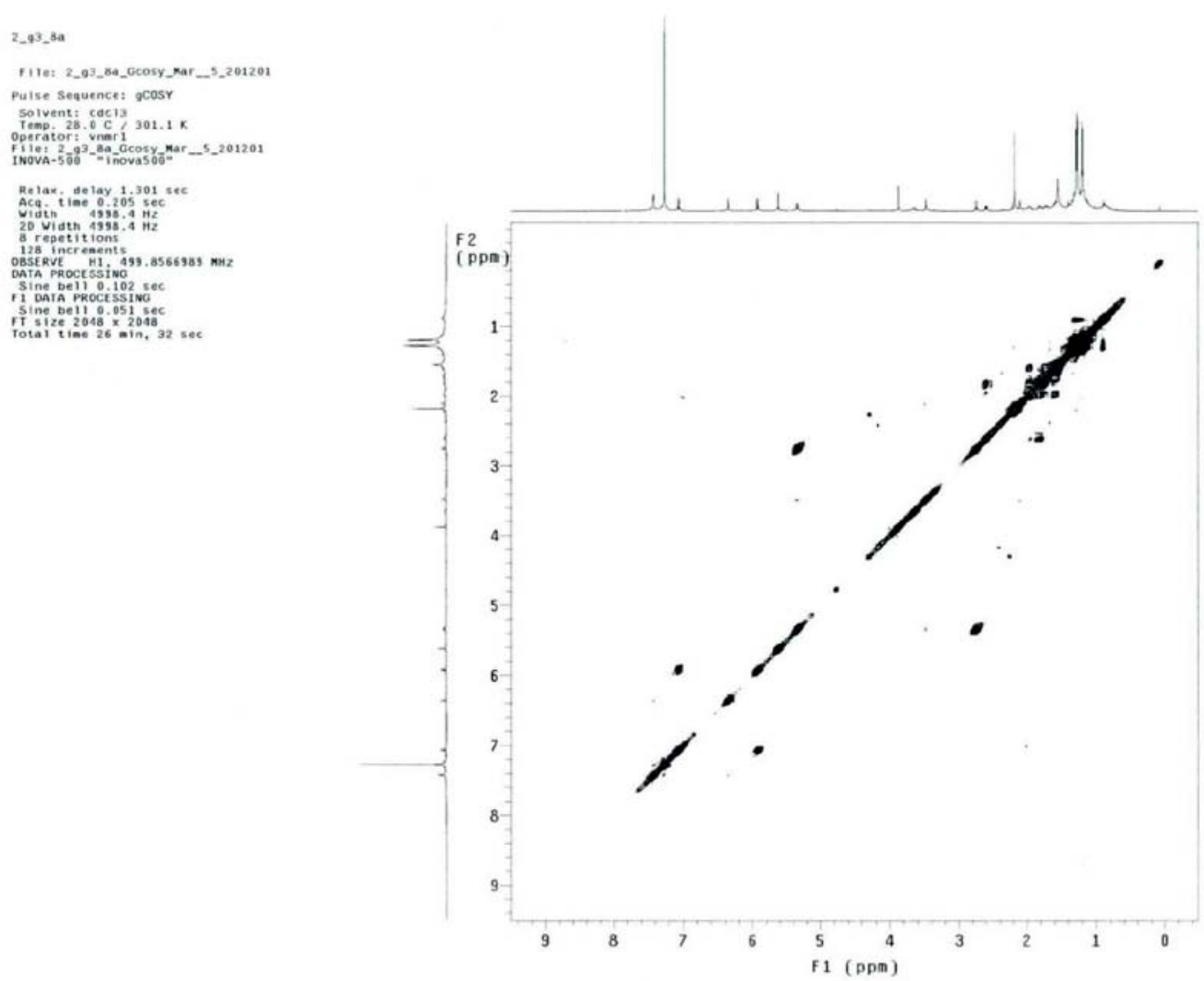

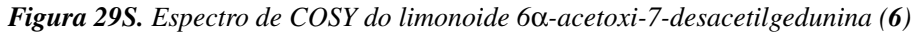

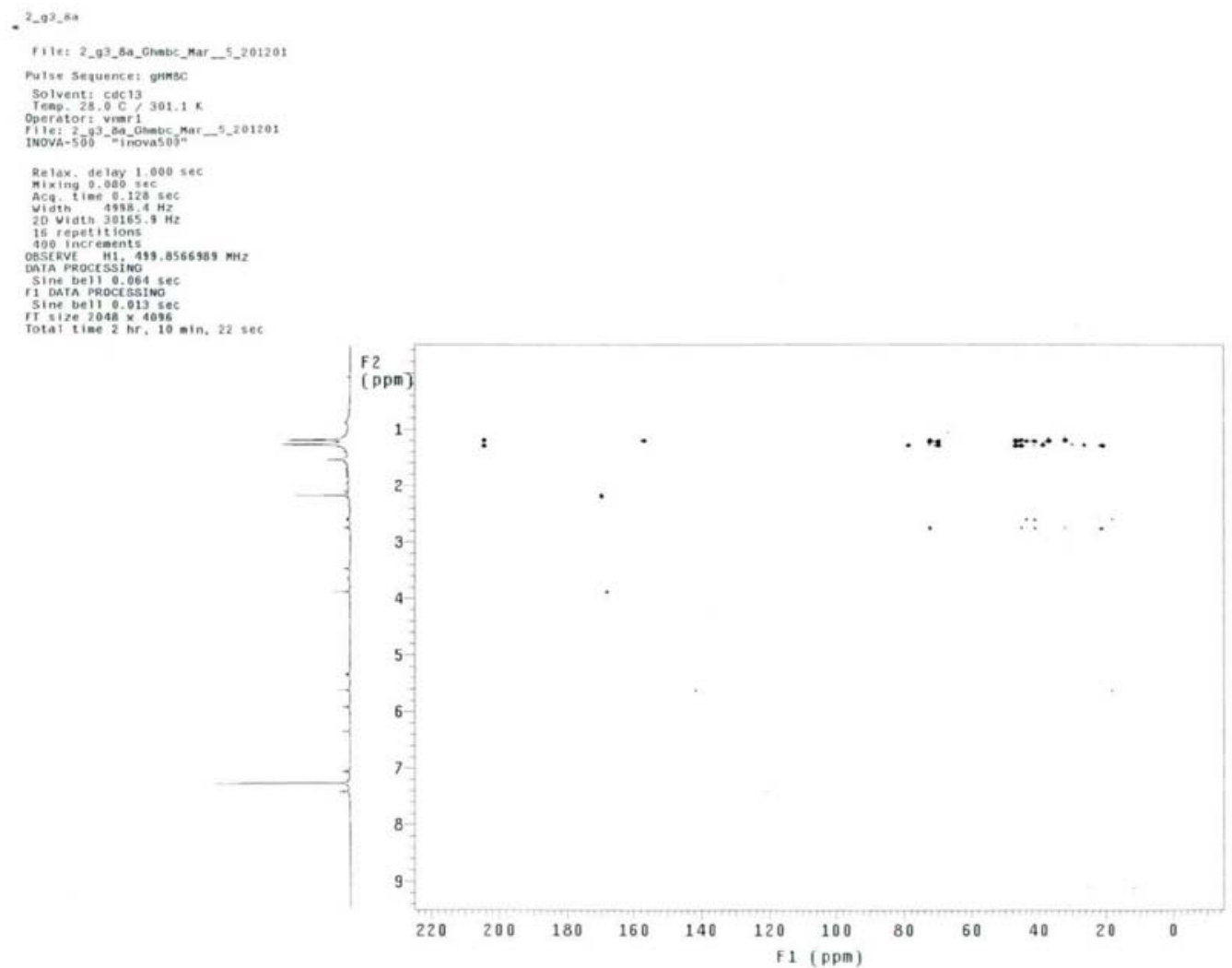

Figura 30S. Espectro de HMBC do limonoide $6 \alpha$-acetoxi-7-desacetilgedunina (6) 


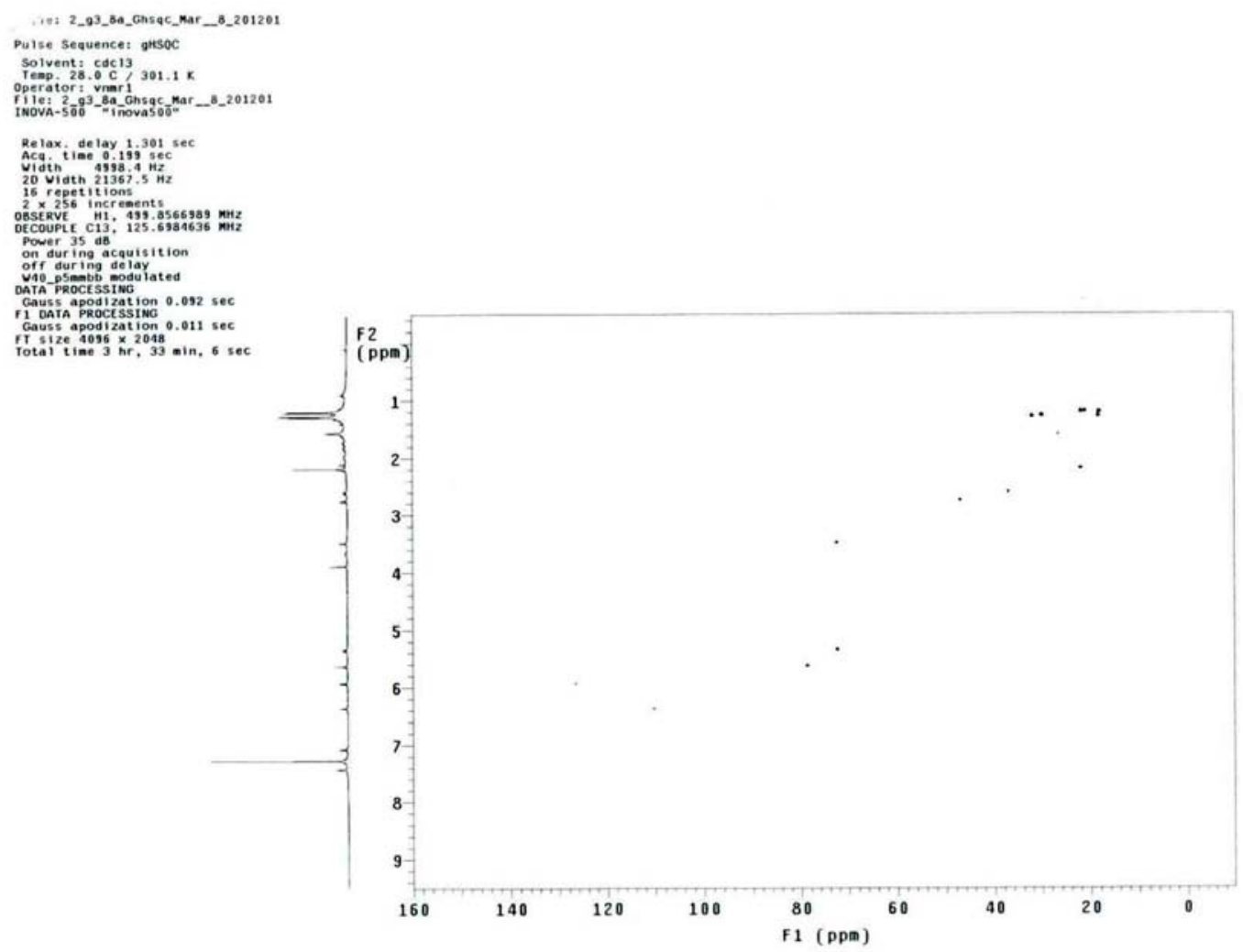

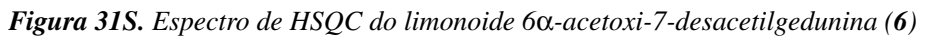

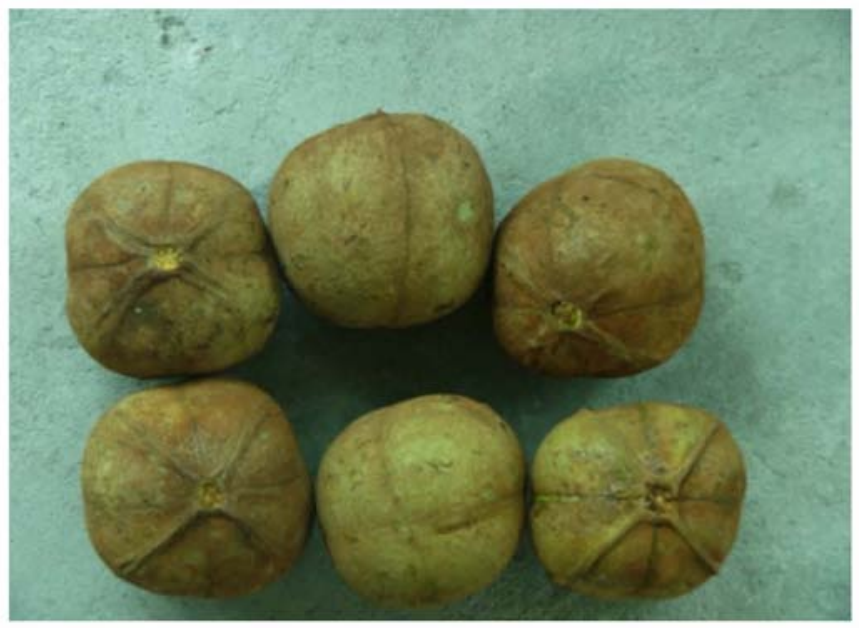

Figura 32S. Frutos de Carapa guianensis coletados na reserva Adolpho Ducke, Manaus, AM 


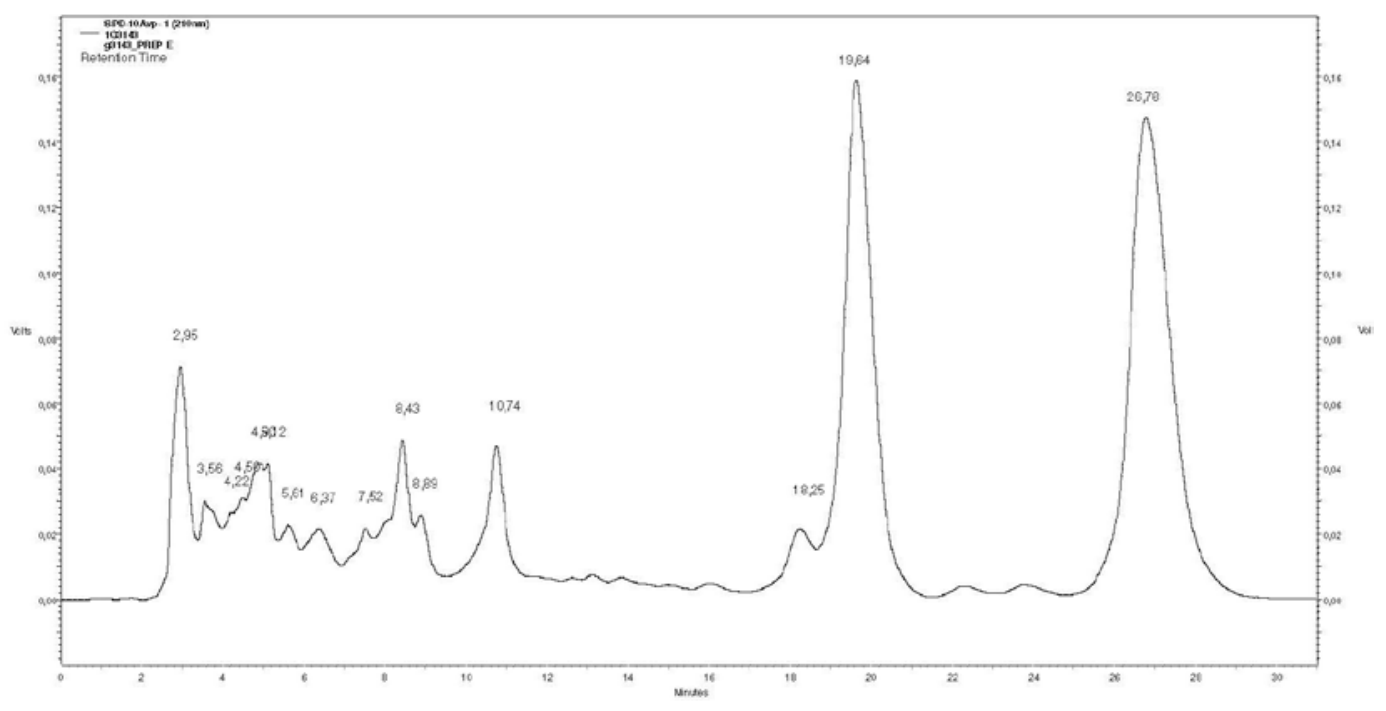

Figura 33S. Cromatograma obtido para o isolamento dos limonoides 5 e 6 